\title{
Organisationale Strukturveränderungen und berufliche Identitätsbehauptung - Gegenstand und Anlage der Untersuchung
}

Die deutschen Universitäten sind seit Ende der 1990er-Jahre mehreren großangelegten Reformen gleichzeitig unterzogen worden (Bogumil und Heinze 2009; Schimank 2012a; Hüther und Krücken 2016, S. 50-61). Bezüglich der Lehre lautet das Stichwort „Bologna“: eine grundlegende Veränderung der Studienstrukturen mit entsprechend veränderten Anforderungen an die Lehre. Auch die zweite Hauptaufgabe der Universitäten, die Forschung, ist zur selben Zeit mit neuartigen ,Herausforderungen ${ }^{6}$ - wie man so sagt - konfrontiert worden, wofür die „Exzellenzinitiative“ das tonangebende Vorhaben ist. Und schließlich hat es unter der Parole des „New Public Management“ (NPM) weitreichende Umbauten der Entscheidungsstrukturen des deutschen Hochschulsystems gegeben - sowohl innerorganisatorisch in jeder Universität als auch interorganisatorisch im Verhältnis der Universitäten zu den staatlichen Trägern. Schon die weitgehend unabgestimmte Parallelität dieser drei gleichermaßen ambitionierten Reformvorhaben hat vielerlei teilweise unvorhergesehene Wechselwirkungen nach sich gezogen, die neben den inhärenten Widersprüchlichkeiten jeder der Reformen für eine Gemengelage ambivalenter Effekte gesorgt haben: wenig allseits Gewolltes, Einiges zumindest von einer Seite Gewolltes und nicht Weniges, was keiner so gewollt hat. Noch dazu hat das alles unter Bedingungen einer starken Unterfinanzierung des Hochschulsystems stattgefunden, was sich für die Lehre in vielen Fächern in einer verschlechterten Betreuungsrelation - Studierendenzahl pro Lehrenden (Wissenschaftsrat 2018, S. 19) - und für die Forschung in einer steigenden Drittmittelabhängigkeit manifestiert (Aljets 2015, S. 84-91). Beides zeigt, dass die finanzielle Grundausstattung der Universitäten durch die Bundesländer als deren Träger immer unzureichender geworden ist (Dohmen und Wrobel 2018). Es ist eigentlich eine Organisationsleitungen und politischen Entscheidungsträgern bekannte Binsenweisheit, dass großangelegte Reformen umso schwieriger und umso 
weniger Erfolg versprechend sind, unter je größerer Finanzknappheit sie vollzogen werden; denn wenn man genügend Geld hat, kann man Härten abfedern und Widerstände ,abkaufen'. Doch die deutsche Hochschulpolitik hat sich in genau dieses Abenteuer gestürzt: Alles sollte zum Nulltarif ganz anders werden.

Vielleicht war das ja angesichts der jahrzehntelangen Reformblockaden eines „,verrotteten“ Hochschulsystems - so eine bekannte und von vielen geteilte Einschätzung des Vorsitzenden des Wissenschaftsrats, Dieter Simon (1991), Anfang der 1990er Jahre - überfällig. ${ }^{1}$ Wie dem auch sein mag: Nun ist damit umzugehen, was das Reformstakkato ohne ausreichende finanzielle Grundlage hervorgebracht hat. Die Schlüsselgruppe unter den involvierten Akteuren, die sogleich ins Auge fällt, sind die Professorinnen und Professoren. Klar ist: Wenn sie nicht mitmachen, laufen alle Reformen ins Leere. Ähnlich wie Richterinnen in Gerichten oder Chefärzte in Krankenhäusern sind ProfessorInnen ein Berufsstand, an dessen Engagement das Wohl und Wehe der Organisationen, in denen sie tätig sind, hängt. Die Leistungsproduktion der Universitäten in Lehre und Forschung - in Gestalt von auf dem Arbeitsmarkt nachgefragten AbsolventInnen sowie von Forschungsergebnissen in von FachkollegInnen zitierten Publikationen - wird auf der Arbeitsebene maßgeblich von den ProfessorInnen getragen. ${ }^{2}$ Das geschieht teils dadurch, dass sie selbst die betreffenden Leistungen erbringen, und teils dadurch, dass sie die Leistungsproduktion der ihnen untergeordneten wissenschaftlichen MitarbeiterInnen anleiten. Vor diesem Hintergrund stellt sich die Frage: Welche Auswirkungen haben die Reformen auf die Arbeitsbedingungen und Arbeitsmotivation der ProfessorInnen gehabt?

Man erhält diametral entgegengesetzte Antworten auf diese Frage - je nachdem, wen man fragt. Um die Extreme, etwas karikaturistisch zugespitzt, vorzustellen:

- Die Promotoren der Reformen, etwa in den zuständigen Ministerien oder beim Centrum für Hochschulentwicklung der Bertelsmann-Stiftung (CHE), dem

\footnotetext{
${ }^{1}$ Fünf Jahre später wurde dieser Einschätzung von Peter Glotz (1996 - Zitate: 135), seines Zeichens Bildungspolitiker und Gründungsrektor der wiedererrichteten Universität Erfurt, ein ganzes Buch gewidmet, das die These ,im Kern verrottet“ zur Frage wendet und zu dem Fazit gelangt, die deutsche Universität sei zwar „längst nicht mehr gesund“, aber noch heilbar ,krank“.

${ }^{2}$ Womit natürlich nicht gesagt werden soll, dass die Beiträge der anderen Mitarbeitergruppen nicht auch wichtig sind. Quantitativ wird die Hauptarbeit durch den - zahlenmäßig weitaus größeren - Mittelbau geleistet. Doch die ProfessorInnen sind diejenigen Akteure mit der größten „Einflussstärke auf die operationalen Abläufe der Universitätsorganisation“ (Kleimann 2016b, S. 197).
} 
wichtigsten einschlägigen Think Tank, betonen, dass es höchste Zeit gewesen sei, , verwöhnten' ProfessorInnen, die überdies nicht mehr zeitgemäßen Vorstellungen verhaftet gewesen seien, Beine gemacht $\mathrm{zu}$ haben. Neue Leitlinien für , gute 'Forschung und, gute‘ Lehre seien etabliert worden; und eine Bewertung von Forschung und Lehre gemäß diesen Leitlinien habe dazu geführt, dass diejenigen, die gut abschneiden, sowohl in der Ressourcenausstattung ihrer Professur als auch in ihrem persönlichen Einkommen profitieren, während die weniger Leistungsfähigen oder -willigen Einbußen erleiden. Dies werde ihnen hoffentlich nicht nur eine Lehre sein, sondern sei auch noch höchst effizient: werde das Geld dadurch doch bestmöglich, also dort, wo es den meisten Nutzen bringe, investiert. ${ }^{3}$

- Viele ProfessorInnen halten dagegen, dass alle drei Reformen überflüssig und sogar schädlich für die Leistungsproduktion in Forschung und Lehre seien. Die bisherigen Strukturen seien durchaus leistungsfähig gewesen und völlig zu Unrecht denunziert worden. Woran es in Wirklichkeit mangele, sei eine auskömmliche Grundfinanzierung der Universitäten - darüber täusche die Politik durch ihr Insistieren auf angeblich dringend erforderlichen Reformen nur hinweg.

Um zu verstehen, wieso es solch konträre Deutungen überhaupt geben kann, muss man sich bewusst machen, dass UniversitätsprofessorInnen einem in vielen Hinsichten privilegierten Berufsstand angehören. Die allermeisten sind bei ihrer Forschung hochgradig intrinsisch motiviert, viele auch bei der Lehre, ${ }^{4}$ und ziehen

\footnotetext{
${ }^{3}$ Eine in dieser Hinsicht richtungsweisende Veröffentlichung stellte etwa die des damaligen Leiters des CHE, Detlef Müller-Böling (2000 - Zitate: 11; 69), dar, der Anfang des Jahrtausends seine Reformvision einer „entfesselten Hochschule“ zeichnete. Müller-Böling geht es dabei um eine „Entfesselung aus den verschiedensten Umarmungen [...], die die Hochschulen derzeit noch erstick[t]en“, was eben auch bedeute, sie stärker als „Dienstherren“ in die Verantwortung zu nehmen. Das Argument der ,faulen“ ProfessorInnen wird dabei umgekehrt in eines der Fairness und „Ehrlichkeit des Systems“ - denn Leistung müsse sich auch an Hochschulen „lohnen“. Für eine kritische Auseinandersetzung mit der „entfesselten Hochschule“ 20 Jahre nach ihrem Erscheinen siehe Alfred Kieser (2020).

${ }^{4}$ Dass dem so ist, wird im Zuge der Umsetzung der NPM-Reformen aber vermehrt hinterfragt. So haben sich verschiedene AutorInnen der Frage des Einflusses der Reformen auf die Arbeitsmotivation sowie möglicher Verdrängungseffekte durch Ziel- und Leistungsvereinbarungen angenommen. Während Margit Osterloh und Bruno Frey (Osterloh 2010; Osterloh und Frey 2015) die Reduzierung der intrinsischen Motivation von Forschenden durch externe Anreize seit längerer Zeit kritisch verzeichnen, schätzen Uwe Wilkesmann und Christian Schmid (2014) die Auswirkungen der W-Besoldung und Leistungsvereinbarungen auf die intrinsische Lehrmotivation als derzeit noch insgesamt gering ein.
} 
neben großer innerer Befriedigung soziale Anerkennung aus beiden Tätigkeiten. ProfessorInnen genießen überdies eine hohe Arbeitsautonomie, die in Deutschland durch den Grundgesetzartikel 5, Absatz 3 verfassungsrechtlich abgesichert ist. Hinzu kommen die Unkündbarkeit von BeamtInnen und ein Gehalt, das zwar nicht so hoch ist wie auf vergleichbaren Positionen in Unternehmen, aber doch sehr auskömmlich. Diese positiven Seiten ihres Berufs werden von ProfessorInnen durchaus gesehen, und nicht wenige stufen sich im Vergleich zu den Angehörigen anderer Berufe als ausgesprochen begünstigt ein. ${ }^{5}$

Und dennoch ist unüberhörbar, dass ProfessorInnen in den zurückliegenden zwanzig Jahren zunehmend darüber klagen, dass sie sich bei ihrer Berufsausübung unzulässig überwacht, gegängelt, gar drangsaliert vorkommen - und zwar von Leuten, die in ihren Augen nicht die geringste Ahnung davon haben, was ,gute" Forschung und, gute' Lehre erfordern und was sie jeweils ausmacht. Nicht nur, aber geballt in der Zeitschrift Forschung und Lehre (F\&L) des Deutschen Hochschulverbands (DHV), der die Standesorganisation der deutschen UniversitätsprofessorInnen ist, findet man Monat für Monat Erfahrungsberichte und Meinungsartikel, in denen ProfessorInnen mit ihrem Unmut über „Bologna“, Exzellenzwettbewerbe und NPM nicht hinter dem Berg halten. Um nur die Überschriften zweier Beiträge zu zitieren: „Der gefesselte Professor“ von Thomas Ehrmann (9/2015) oder: „Im Absurdistan der Leistungsberechnung“" von Andreas Gold (11/2015).

Drücken sich in einer solchen Kritik nur Wehwehchen von Verwöhnten aus, die nicht verwinden können, dass sie sich gesellschaftlich und in der Universität schon lange nicht mehr als „Mandarine“ - wie Fritz Ringer (1987) die deutsche Professorenschaft des Kaiserreichs charakterisiert hat - ,aufspielen“ können? So sehen es die Promotoren der Reformen. In deren Augen stilisieren sich die ProfessorInnen zu Opfern, womit sie in Wirklichkeit bloß überkommene

\footnotetext{
Zwar schmälerten Leistungsvereinbarungen, anders als Leistungszulagen, die intrinsische Motivation zu lehren, gleichwohl sei letztere als immer noch vergleichsweise hoch und als die dominierende Form der Motivation anzusehen.

${ }^{5}$ Dies wird auch immer wieder in den meist standardisierten Befragungsstudien zu Arbeitsbedingungen und -zufriedenheit der ProfessorInnen in Deutschland herausgestellt - so etwa in der deutschen Teilstudie des international vergleichenden „Changing Academic Profession“-Projektes (Jacob und Teichler 2011; Höhle und Teichler 2013) oder in der von der HRK in Auftrag gegebenen und auf die Lehre fokussierenden LESSI-Studie von Harald Schomburg et al. (2012). Dass solche Untersuchungen zu den Auswirkungen der Reformen jedoch nur begrenzt aussagefähig sind, greifen wir an späterer Stelle nochmal auf.
} 
Privilegien sichern wollen. Schlimmer noch: Nicht wenige ProfessorInnen - so hört man es hinter vorgehaltener Hand etwa von für die Universitäten zuständigen MinisterialbeamtInnen - suhlten sich geradezu im rückwärtsgewandten Selbstmitleid, anstatt ihren Beitrag zur ,Erneuerung ' der Universitäten zu leisten und auch die damit verbundenen eigenen Chancen zu ergreifen.

In diesem hoch kontroversen Meinungsspektrum bewegt sich die vorliegende Untersuchung. Sie fragt danach, wie UniversitätsprofessorInnen verschiedener Fächer die genannten Reformen erfahren und wie sie diese in ihrem beruflichen Handeln praktisch verarbeiten. Man kann annehmen, dass ProfessorInnen, wie Angehörige anderer Berufe auch, als Teil ihrer beruflichen Identität Vorstellungen darüber haben, wie , gute' Arbeit auszusehen hat. Wie sehen diese Vorstellungen über ,gute' Lehre und Forschung aus? In welchen Hinsichten haben die Effekte der Reformen diese Vorstellungen verletzt? Wie gehen die ProfessorInnen mit diesen Irritationen, vielleicht gar Bedrohungen, ihrer beruflichen Identität um? Haben sie ihre Identität an die neuen Verhältnisse angepasst, oder versuchen sie auf die eine oder andere Weise, ihre Identität gegen die Verhältnisse zu behaupten? Und wie stellen sich die Praktiken der Anpassung oder des Widerstands im Arbeitsalltag dar?

Die Fragestellung so zu entfalten unterstellt freilich, dass die Reformen als überwiegend problematisch erfahren werden. Auch wenn dies dem Tenor vieler öffentlich artikulierter Meinungen aus der Professorenschaft entspricht, ${ }^{6}$ sollte man weiterhin fragen, ob es nicht daneben Fälle gibt, die Gegenteiliges zeigen. Könnten die Reformen nicht vielleicht auch Wasser auf den Mühlen bestimmter Ausprägungen der beruflichen Identität von ProfessorInnen sein? Sofern man auch dies vorfindet, wird es umso interessanter sein, danach zu fragen, von welchen Faktoren es denn abhängt, ob ProfessorInnen eher negativ oder eher positiv von den Universitätsreformen der zurückliegenden zwanzig Jahre betroffen sind. Liegt es am Fach? An der Karrierephase? Am Geschlecht? Oder an noch anderen Determinanten?

Systematischer lassen sich diese Fragen in einem analytischen Dreischritt entfalten:

\footnotetext{
${ }^{6}$ Es entspricht im Übrigen auch der referierten Einschätzung der Reformpromotoren - nur mit umgekehrter Bewertung: Die ProfessorInnen sollen gefälligst umlernen, also ihr berufliches Selbstverständnis den Reformen anpassen - oder zumindest, wie es Müller-Böling (2000 - Zitate: 38) formulierte, ihre ,individuellen Autonomieansprüche“ zugunsten der „korporative[n] Autonomie der Hochschule als Ganzes“ zurückstellen.
} 
1) Wie wirken sich die durch die Reformen hervorgerufenen Strukturveränderungen im deutschen Hochschulsystem auf die berufliche Identität von ProfessorInnen aus?

2) Insoweit es nennenswerte - negative oder positive - Auswirkungen gibt: Wie gehen die ProfessorInnen damit um?

3) Dabei interessiert besonders: In welchen Praktiken zeigen sich Bemühungen, berufliche Identitätsansprüche gegenüber den Strukturveränderungen in Lehre und Forschung zu behaupten?

Hauptergebnis der Untersuchung wird eine differenzierte Typologie von ProfessorInnen entsprechend ihren unterschiedlichen Reformerfahrungen und Praktiken des Umgangs mit den Reformen sein - anstelle sehr simplifizierender Kontraste von Opfern und Profiteuren der Reformen. Aus mindestens drei Gründen ist die Typologie, die wir aus der Empirie erarbeiten werden, wichtig für die weitere Forschung über Hochschulen und deren Reformen, aber auch für die weiteren praktischen Bemühungen um eine Gestaltung dieser Reformen. Erstens liefert eine der vielschichtigen Empirie gerecht werdende typologische Charakterisierung von ProfessorInnen eine adäquatere Beschreibung und Erklärung dessen, wie sich Reformdynamiken und Professorenschaft zueinander verhalten haben. Zweitens ist diese Typologie die notwendige Voraussetzung dafür, in weiteren Untersuchungen die zahlenmäßige Verteilung der ProfessorInnen auf diese Typen ermitteln zu können und womöglich die Reformdynamiken auch als einen Wandel des Verteilungsmusters nachvollziehen zu können. Vielleicht haben ja bestimmte Typen anfangs überwogen, sind dann jedoch weniger geworden, während andere Typen im Zuge der Reformen zugenommen haben. Drittens schließlich kann, auf den beiden ersten Punkten aufbauend, die weitere Gestaltung der Reformen zielgenauer angegangen werden - wobei wohlgemerkt nicht nur an eine Gestaltung, von oben', also durch die Hochschulpolitik und die Universitätsleitungen, sondern ebenso an eine ,GegenGestaltung' durch Interessenpolitik der ProfessorInnen oder von Teilen der Professorenschaft zu denken ist.

Wenn damit die Thematik und Relevanz der empirischen Studie, deren Ergebnisse wir hier berichten, ${ }^{7}$ erst einmal angedeutet sind, werden wir in diesem

\footnotetext{
${ }^{7}$ Die Studie wurde vom Bundesministerium für Bildung und Forschung im Rahmen der Förderlinie „Leistungsbewertung in der Wissenschaft“ unter dem Projekttitel „Einfluss von Leistungsbewertungen auf die Integration von Lehre und Forschung im Fächervergleich“ an der Universität Bremen vom Januar 2014 bis zum Dezember 2016 gefördert.
} 
Kapitel nun zunächst die empirischen und theoretischen Ausgangspunkte der Analyse genauer vorstellen. Wir schildern dazu im ersten Abschnitt die mit den erwähnten Reformen einhergehenden organisationalen Strukturveränderungen und fragen danach, welche Auswirkungen auf die berufliche Identität damit verbunden sein könnten. Im zweiten Abschnitt skizzieren wir ein theoretisches Instrumentarium für die Analyse individueller beruflicher Identitätsbehauptung. Der dritte Abschnitt erläutert das empirische Vorgehen, mit dem wir die angesprochenen Fragen angegangen sind. Das Kapitel schließt mit einer Vorschau auf die Ergebnispräsentation in den weiteren Kapiteln.

\subsection{Organisationale Strukturveränderungen der Universitäten}

Was in den letzten zwanzig Jahren unter den genannten Stichworten NPM, „Bologna“ und „Exzellenzinitiative“ als Strukturveränderungen an den deutschen Hochschulen stattgefunden hat, war keine Reform aus einem Guss. Weder hinsichtlich der angegangenen sachlichen Issues noch hinsichtlich des zeitlichen Prozederes gab es einen übergreifenden abgestimmten Masterplan. Das hat weniger der sonst übliche Verdächtige, der deutsche Föderalismus, verhindert, durch den 16 Bundesländer als Träger ihrer Universitäten je für sich wesentliche Letztentscheidungsrechte über deren Gestaltung ausüben - einschließlich der Entscheidung darüber, welchen Gestaltungseinflüssen anderer Akteure sie ihre Universitäten aussetzen. Schon vorgelagert war vielmehr entscheidend, dass alle drei Reformen von ganz unterschiedlichen Akteuren konzipiert und propagiert wurden, zwischen denen es diesbezüglich wenig Austausch gab.

Am frühesten setzte Ende der 1990er Jahre NPM ein. Wie der Name schon sagt, war dies keine hochschulspezifische Reform, sondern eine den ganzen öffentlichen Sektor betreffende Neugestaltung von Governance-Strukturen. Nicht die Universitäten, sondern andere Bereiche wie die Kommunalverwaltung oder die öffentlichen Krankenhäuser kamen zuerst dran (OECD 1995; Pollitt und Bouckaert 2000, 2017); und Deutschland war keiner der Vorreiter, sondern ein Nachzügler (Schimank und Lange 2009). NPM war inspiriert von den neoliberalen Ideen, die seit Mitte der 1970er Jahren zuerst in den angelsächsischen Ländern Fuß gefasst hatten, und wurde dann auch durch internationale Organisationen wie die OECD weiter propagiert.

Es folgte um die Jahrtausendwende „Bologna“ als weitreichende Umgestaltung der Studienstrukturen. Auch hier waren, wiederum von der OECD mit initiierte, generelle bildungspolitische Reorientierungen ein wichtiger Anstoß, 
der dann von den europäischen Staaten als neu zu schaffender „europäischer Hochschulraum" umgesetzt wurde (Witte 2006; HIS 2010; Hillmer und AlShamery 2015). In Deutschland war es insbesondere das Bundesministerium für Bildung und Forschung (BMBF), das die zunächst überwiegend wenig aktiven Bundesländer als Träger der Hochschulen dazu brachte, die alten Studienstrukturen abzuschaffen und die neuen zu etablieren (Friedrich 2006).

Schließlich kam kurz darauf auch die „Exzellenzinitiative“. Die ursprüngliche Idee des BMBF, eine ganz kleine Zahl von sehr forschungsstarken Universitäten wesentlich besser mit Forschungsmitteln auszustatten, ließ sich zwar gegen den Widerstand der Länder so nicht umsetzen. Stattdessen ist seitdem in erheblichem Maße zusätzliches Geld für die Förderung größerer Forschungsverbünde bereitgestellt worden, das in einem kompetitiven Verfahren breiter gestreut als zunächst beabsichtigt, aber dennoch alles andere als mit der sprichwörtlichen Gießkanne verteilt wird (Lange und Schimank 2006, S. 336-340; Leibfried 2010; Leibfried und Schreiterer 2015).

Die Ideenwelt, in der diese Hochschulreformen geboren wurden, war eine neoliberale. ${ }^{8}$ Das gilt nicht nur, wie schon erwähnt, für NPM, sondern ebenso für die anderen beiden Reformen. Entsprechend sahen das Menschenbild, das zugrunde gelegt wurde, und die Vorstellungen darüber aus, was man wie umgestalten müsste. Im Zentrum steht das institutionenökonomische Principal-Agent-Modell, das Leistungsproduktionen in Organisationen als soziale Beziehungen zwischen Leistungserbringern als Agenten und deren Leistungsabnehmern bzw. den diese repräsentierenden Organisationsleitungen als Prinzipalen betrachtet (Moe 1984; Ebers und Gotsch 1998, S. 209-225; mit Blick auf Hochschulen Wilkesmann und Schmid 2012; Wilkesmann 2013; Kivistö und Zaljevska 2015). Dabei wird die Blickrichtung vom Prinzipal auf die Agenten eingenommen. Es geht darum, deren Handeln zu beurteilen und auf die Linie dessen, was der Prinzipal will, zu bringen. Seine Ziele, Maßstäbe und Erwartungen stehen hingegen nicht zur Disposition.

ProfessorInnen werden demzufolge als eigeninteressierte Agenten angesehen, die - wie es angeblich Frederick Taylors (1913) Fließbandarbeiter oder George Akerlofs (1970) Gebrauchtwagenverkäufer tun - ihren Prinzipalen, also den Abnehmern ihrer Leistungen in Lehre und Forschung sowie ihren Organisationsleitungen, auf möglichst bequeme Weise weis machen wollen, dass die jeweilige

\footnotetext{
${ }^{8}$ Siehe dazu als allgemeine und unterschiedlich bewertende Überblicke Gerhard Willke (2003), Stephanie Lee Mudge (2006) und Ralf Ptak (2007).
} 
Leistung erbracht worden ist. Plakativ überspitzt: Alle ProfessorInnen wollen sich demzufolge um die Lehre drücken und als DünnbrettbohrerInnen den KollegInnen aufgeputzte Trivialitäten als epochale Forschungsergebnisse unterjubeln. ${ }^{9}$ Das Modell ist also von Zweifeln an der Leistungsfähigkeit, vor allem aber an der Leistungsbereitschaft des Agenten - in unserem Fall: „Professor Untat“ (Kamenz und Wehrle 2007) - geprägt. Die zu ziehende Schlussfolgerung liegt auf der Hand: Es muss um eine „Disziplinierung des Agenten“ (Ebers und Gotsch 1998, S. 214 - Hervorheb. weggel.) gehen. Damit die Prinzipale besser zu ihrem Recht kommen können, empfehlen sich Leistungskontrollen und Leistungsmessungen sowie eine an deren Resultaten orientierte Belohnung , guter' und Bestrafung, schlechter' Leistungen.

Längst nicht alle Elemente der Reformen lassen sich auf den Generalnenner der Leistungsbewertung bringen. Es gibt auch ganz anders ausgerichtete Maßnahmen in jedem der drei Vorhaben. Doch im NPM und auch in der „Exzellenzinitiative“ bilden Maßnahmen der Leistungsbewertung von Individuen, Organisationseinheiten und Organisationen als Ganzen den expliziten Dreh- und Angelpunkt. In „Bologna“ scheint Leistungsbewertung auf den ersten Blick weniger zentral zu sein; dieser falsche Eindruck ergibt sich aber nur daraus, dass die fundierende Leistungsbewertung hier in Gestalt einer pauschalen Abwertung professoraler Vorstellungen, guter' Lehre am Anfang des Reformprozesses als nicht mehr infrage gestellte Prämisse stand. Im Einzelnen handelt es sich um ein Bündel aus acht Arten von Strukturveränderungen, die nun vorgestellt werden wobei dies kurz gehalten werden kann, weil sie allesamt den Eingeweihten und Betroffenen mittlerweile gut vertraut sind. ${ }^{10}$

\section{„New Public Management“}

Mit den durch NPM eingeführten Veränderungen beginnend, ${ }^{11}$ lässt sich als erstes das Instrument der Zielvereinbarungen nennen, die zwischen den zuständigen Landesministerien und deren Hochschulen, dann aber auch hochschulintern zwischen Leitung und Fachbereichen sowie mit einzelnen ProfessorInnen

\footnotetext{
${ }^{9}$ Eine solche Deutung impliziert natürlich, dass die Lehre von den meisten als der Forschung nachgeordnet angesehen werde, was zu prüfen ist. Dass diese Einschätzung dem Tenor der ReformbefürworterInnen entspricht, zeigt die mediale Berichterstattung, die wir in Kap. 2 nachzeichnen.

${ }^{10}$ Siehe als ersten Überblick Jörg Bogumil und Rolf Heinze (2009).

${ }^{11}$ Siehe als Überblicke Uwe Schimank und Stefan Lange (2009), Schimank (2009), Bogumil et al. (2013), Otto Hüther und Georg Krücken (2016, S. 136-151).
} 
geschlossen werden (Jaeger et al. 2005; Nickel 2007). In Zielvereinbarungen werden Leistungsziele zwischen Prinzipal und Agent formuliert, zu deren Erreichung sich Letzterer verpflichtet; im Gegenzug erhält dieser Ressourcen zur Zielverfolgung sowie gegebenenfalls auch eine erfolgsabhängige Prämie als Teil des eigenen Gehalts. Einzelne ProfessorInnen können direkt oder indirekt von Zielvereinbarungen betroffen sein. Ersteres ist dann der Fall, wenn mit ihnen individuelle Zielvereinbarungen, etwa bei Berufungs- oder Ausstattungsverhandlungen, getroffen werden. Eine indirekte Betroffenheit ist dann gegeben, wenn ein Professor ${ }^{12}$ nicht selbst Adressat einer Zielvereinbarung ist, aber bestimmte Effekte etwa einer zwischen Ministerium und Universitätsleitung getroffenen Zielvereinbarung bis zu ihm durchschlagen. So kann die Universitätsleitung dem Ministerium beispielsweise zusagen, dass ein bestimmtes Fach sich in den kommenden Jahren um die Einwerbung eines Sonderforschungsbereichs bemühen wird, wofür es im Gegenzug eine dafür benötigte zusätzliche Professur erhält. Selbst wenn die FachvertreterInnen vor dieser Vereinbarung gefragt wurden und mehrheitlich zugestimmt haben, stehen sie fortan unter dem Druck, die je eigenen Forschungspräferenzen auf den zu konzipierenden Sonderforschungsbereich hin auszurichten - und das gilt oft auch für diejenigen, die diesem Vorhaben eher ablehnend gegenüberstehen.

Zielvereinbarungen sind ein Instrument der Steuerung eines Akteurs durch einen anderen. Ein zweites Instrument dafür sind im Hochschulsystem die neu eingeführten Hochschulräte (Mayntz 2002; Bogumil et al. 2007; Hüther 2009; Jochheim et al. 2016). An sie haben die Ministerien einen Teil der Befugnisse delegiert, die sie zuvor selbst als Repräsentanten der Prinzipale hatten. Das können Aufsichts-, Genehmigungs- oder Entscheidungsbefugnisse sein. Normalerweise gibt es keinen direkten Durchgriff der Hochschulräte auf einzelne Professuren; doch indirekt können die Einwirkungen eines Hochschulrats auf die Hochschule dann auch Auswirkungen auf die Arbeitsmöglichkeiten einer Professorin haben, wenn der Hochschulrat beispielsweise bei Profilbildungsentscheidungen oder bei Entscheidungen über die Vergaberichtlinien für Leistungszulagen mitwirkt. Der Hochschulrat kann ausschließlich aus externen Mitgliedern oder aus einer Mischung externer und interner Mitglieder bestehen. Bei den Externen kann man erhoffen, dass sie neutral und vermittelnd in hochschulinternen Konflikten z. B. zwischen Fachbereichen oder zwischen Fächern und der Universitätsleitung auftreten; als Kehrseite dessen muss man davon aus-

\footnotetext{
${ }^{12}$ Wir verwenden im Weiteren die männliche und die weibliche Form auch alternierend.
} 
gehen, dass ihnen viel lokales Wissen fehlt und sie deshalb sehr abhängig von den Informationen der Universitätsleitungen sind, die selbst Konfliktparteien sein können. ${ }^{13}$

Flächendeckend wurde drittens eine leistungsorientierte Mittelverteilung (LOM) von mehr oder weniger großen Anteilen der Grundausstattung der Hochschulen eingeführt (Leszczensky und Orr 2004; Jaeger et al. 2005; Lange 2008). Dies hat die bis dahin gängige hauptsächlich auslastungsbezogene Zuteilung der Grundausstattung vom zuständigen Landesministerium an die einzelnen Hochschulen abgelöst. Anhand von auferlegten Performanzindikatoren, die mit unterschiedlichen Gewichtungen in eine Formel eingehen, erhalten die Universitäten je nachdem, wie sie in den letzten drei bis fünf Jahren relativ zu den anderen Universitäten des Landes abgeschnitten haben, ihren - unter Umständen von Bemessungsperiode zu Bemessungsperiode schwankenden - Anteil am vorgesehenen Gesamtbudget des Landes für das Hochschulsystem. Übliche Performanzindikatoren sind Absolventenzahlen und Drittmitteleinwerbungen, anfangs wurde oft auch die Anzahl der Promotionen gewertet. Die Universitätsleitungen haben dann die Möglichkeit, dieselbe Formel bei der internen Weiterverteilung der betreffenden Finanzmittel an die Fachbereiche zu verwenden, was prinzipiell bis auf einzelne Professuren heruntergebrochen werden könnte, oder intern bewusst andere Gesichtspunkte oder Gewichtungen anzuwenden. Es ist leicht auszumalen, dass hierin viel Konfliktpotenzial zwischen Fachbereichen oder sogar einzelnen Professoren liegt - umso mehr, je größer der Anteil dieser leistungsorientiert zugewiesenen Mittel ist. Da freilich relativ fixe Personalkosten sowie allgemeine Verwaltungskosten weiterhin das Gros der Grundausstattung ausmachen, halten sich die Konflikte in Grenzen (Minssen et al. 2003). Doch der allgemeine Druck, bei den eigenen Lehr- und Forschungsaktivitäten einen Beitrag dazu zu leisten, dass die eigene Universität bei der Formel ,punkten“ kann, ist dennoch da, weil in Zeiten immer knapperer Grundausstattung auch geringe Beträge zählen.

Viertens beinhaltet NPM verschiedenste Arten von Evaluationen, die sich als nationale oder internationale Rankings und Ratings von Forschungs- und Lehr-

\footnotetext{
${ }^{13}$ Dass es nicht nur eine erhebliche Varianz hinsichtlich der Entscheidungsbefugnisse der Hochschulräte zwischen den Bundesländern gibt, sondern die Wirkung dieses Instruments auch als eher ernüchternd einzuschätzen sei, stellen Bogumil et al. (2013, S. 87-98) fest. Der Einfluss externer Stakeholder in Gestalt der Hochschulräte müsse so die AutorInnen - vor allem deshalb relativiert werden, weil diese sich vorwiegend aus WissenschaftsvertreterInnen zusammensetzten. Ähnliche Befunde finden sich auch bei Heinke Röbken/Marcel Schütz (2013).
} 
leistungen verbreitet haben und denen Universitätsleitungen und Ministerien immer mehr Beachtung schenken (Whitley und Gläser 2007; Maasen und Weingart 2008). Im Unterschied zur leistungsorientierten Mittelverteilung gibt es - um nur diese drei Beispiele anzuführen - für das Shanghai-Ranking von Universitäten, das CHE-Ranking von Fächern oder den Hirsch-Index, der für individuelle ForscherInnen berechnet wird, keinen formell festgelegten Mechanismus, wie die Evaluationsergebnisse sich in Ressourcenzuweisungen niederschlagen; stattdessen aggregieren sich diese Ergebnisse zu einer neuartigen diffusen öffentlichen Reputation, die nicht mit der traditionellen fachlichen Reputation, wie sie auf der Grundlage von Rezeption durch die jeweilige Scientific Community vergeben wird, zu verwechseln ist, sondern letztere eher verdrängt (Schimank 2010). Unverkennbar spielt das relative Standing einer Universität, eines Fachbereichs oder Fachs oder eines einzelnen Wissenschaftlers, wie es sich aus einzelnen dieser Evaluationen oder aus deren mehr oder weniger systematischer Zusammenschau ergibt, für Berufungslisten, in Ausstattungsverhandlungen, bei Projektanträgen, in der Ressourcenkonkurrenz zwischen Fächern und bei vielen anderen Gelegenheiten eine bedeutsame Rolle und erhält gerade dadurch noch zusätzliches Gewicht, dass man, anders als bei formalisierten Zuteilungsmechanismen, weder vorausberechnen noch nachrechnen kann, was man bekommen wird bzw. hat. Anders gesagt: Die auf solche Evaluationsergebnisse zurückgreifenden Entscheidenden haben Spielraum für Willkür; und man tut gut daran, in möglichst vielen Rankings und Ratings in möglichst allen Hinsichten gut dazustehen, um nicht , auf dem falschen Fuß ${ }^{\star}$ erwischt werden zu können. Wie bei der LOM, aber viel ausgreifender, wird ein entsprechender Druck bis zur einzelnen Wissenschaftlerin weitergegeben, zum einen im eigenen Interesse, zum anderen als Beitrag für das möglichst gute Abschneiden der größeren Einheit, der man angehört - was meist ein Teil des Eigeninteresses ist.

Alle bisher aufgeführten Maßnahmen beinhalten als fünftes Element rapide gestiegene Rechenschaftspflichten bezüglich der je eigenen Lehr- und Forschungsleistungen einer Universität als Ganzer, aber auch ihrer Untereinheiten sowie letzten Endes jeder einzelnen Professur und jedes einzelnen Wissenschaftlers. Dies ist auch die Erfahrung von anderen Berufsgruppen wie ÄrztInnen, die ähnlichen Mechanismen des NPM ausgesetzt sind (Kühn 2004; Böhlke et al. 2009); ${ }^{14}$ und es ist eine hochgradig zwingende Konsequenz, weil

\footnotetext{
${ }^{14}$ Als allgemeinere Diagnose siehe Michael Power (1997 - Zitat: 122), demzufolge die heutige Gesellschaft als „Audit Society“, ,which is increasingly commited to observing itself through various kinds of auditing practices“, charakterisiert werden kann. Kennzeichnend für das von Power skizzierte Gesellschaftsmodell ist nicht zuletzt die Ersetzung des Vertrauens durch Kontrolle der - gerade auch professionellen - Leistungsproduzenten.
} 
sich nur in den seltensten Fällen Leistungsbewertungen allein auf der Grundlage solcher Daten vornehmen lassen, die - wie etwa Zitationen - ohnehin im Prozess der Leistungsproduktion anfallen. Selbst wo solche Rohdaten wie im Beispiel Abfallprodukte wissenschaftlichen Publizierens sind, sprechen sie nicht für sich selbst bzw. sollte man sie im wohlverstandenen Eigeninteresse nicht für sich selbst, etwa zu Universitätsleitungen, sprechen lassen. Allein schon fachliche Spezifika, etwa Publikationsformate (Alexander von Humboldt Stiftung 2009), aber auch lokale Besonderheiten wie etwa interdisziplinäre Kooperationen müssen in Rechnung gestellt werden. Leistungsbewertungen zugrunde gelegte Daten müssen daher zusammengestellt und interpretiert werden, sollen sie eine hinreichende Aussagefähigkeit erhalten; und das sollten die von Leistungsbewertungen Betroffenen nicht allein anderen überlassen, sondern zumindest gegebenenfalls kommentieren, was aber entsprechenden Aufwand bedeutet.

Als sechstes Element von NPM ist schließlich die Einführung der W-Besoldung anzuführen (Detmer und Preißler 2006; Kräkel 2006; Koch 2010). Hierbei geht es darum, dass sich Leistungsstärke in Lehre und Forschung nicht nur bei der Zuteilung von Ressourcen für die weitere Arbeit, sondern auch im persönlichen Einkommen auszahlen soll. Die neue Besoldung besteht aus einer Basiskomponente, die etwa bei drei Vierteln der vergleichbaren bisherigen C-Besoldungsgruppe liegt; bei durchschnittlicher Leistung soll eine Professorin einen Leistungszuschlag erhalten, der das restliche Viertel zur alten Besoldung ausmacht; ,leistungsstärkere' ProfessorInnen können mehr verdienen, ,leistungsschwächere' weniger. Die bisherigen Besoldungserhöhungen gemäß den Dienstaltersstufen entfallen. Die Leistungsbewertung erfolgt darüber, dass ein Professor in regelmäßigen Intervallen von meistens drei Jahren Leistungszulagen beantragen kann und hierfür seine Leistungen in Lehre, Forschung und weiteren Tätigkeitsfeldern dokumentiert; die Hochschulleitung entscheidet am Ende auf Empfehlung aus dem Fachbereich, ob der Antrag bewilligt wird. Wer in der W-Besoldung Einkommenssteigerungen realisieren will, tut gut daran, solche Forschungs- und Lehrleistungen zu erbringen, die im heute vorherrschenden Verständnis, wie es Rating, Rankings und andere Arten von Evaluationen vormachen, ,zählen`. Andere Leistungen bedürfen ausführlicherer Begründung, wobei man nicht weiß, ob sie überhaupt zur Kenntnis genommen wird und überzeugt - was ein Grund dafür sein kann, lieber gleich auf ,Nummer sicher' zu gehen und die ,oben' geschätzten Leistungsnachweise zu erbringen. ${ }^{15}$

${ }^{15}$ Wendy Espeland und Mitchell Stevens (1998) haben an verschiedenen Beispielen „Kommensurierungseffekte“ - also jene Folgen, die sich durch die Transformation unterschiedlicher Qualitäten in eine gemeinsame Metrik zu Zwecken der Vergleichbarkeit ein- 


\section{„Exzellenzinitiative“}

Wirft man nun siebtens einen Blick auf die „Exzellenzinitiative“, stellt sich diese aus der Perspektive auf Leistungsbewertungen als weiteres Format eines besonders kompetitiven und auf großangelegte kooperative Vorhaben ausgerichteten Drittmittelwettbewerbs dar. Dies steht zum einen in einer Entwicklungslinie der bereits angesprochenen, generell immer weiter gestiegenen Drittmittelabhängigkeit von Forschung an den deutschen Hochschulen bei sinkenden Erfolgschancen der Anträge. Zum anderen setzt sich mit der „Exzellenzinitiative“ aber auch ein weiterer Trend fort: weg von sehr autonom konzipierten Einzelprojekten wie beim Normalverfahren der Deutschen Forschungsgemeinschaft (DFG) hin zu Förderformaten wie Sonderforschungsbereichen oder den in den Rahmenprogrammen der EU geförderten Verbünden, wo teils Vorgaben in Bezug auf die Themen, teils aber auch in Bezug auf Kooperation gemacht werden, wobei international und interdisziplinär arbeitende Forschungsverbünde zu den favorisierten Formaten gehören. ${ }^{16}$ Solche Formate sind nicht nur in der Beantragung, sondern auch in der Durchführung einschließlich des Berichtswesens sehr aufwendig. Durch die Verknüpfung mit NPM, das als weiteres Element neben den bereits angesprochenen eine Stärkung der Universitätsleitungen zum Zwecke der gesamtorganisatorischen Profilbildung implementiert hat (Meier und Schimank 2002, 2010, 2014), geht auf die einzelnen Professuren in als profilträchtig angesehenen Forschungsfeldern ein erhöhter Druck, von oben' aus, sichtbare Großvorhaben wie eben nun auch Exzellenzcluster zu konzipieren. In der Konsequenz bearbeiten viele ForscherInnen nicht mehr diejenigen Themen, die ihnen persönlich am wichtigsten und für die sie persönlich am geeignetsten sind. Stattdessen sehen sie sich genötigt, sich in Clusterthemen einzuordnen.

stellen - aufgezeigt, die sich durchaus auf die hier interessierenden Leistungsbewertungen übertragen lassen. In ihrer Analyse stoßen sie gerade auch auf das Problem der Unmöglichkeit der Messbarkeit bestimmter Leistungen, was schnell zu deren Ausschluss aus Kriterienkatalogen und Wertigkeitsordnungen führt.

${ }^{16}$ Siehe zu letzterem etwa die entsprechenden Beschlüsse zu den Rahmenprogrammen der EU, die Kooperation als wesentliches Merkmal der Forschung voraussetzen, und hier insbesondere das spezifische Programm „Zusammenarbeit“ (Europäische Kommission 2006) als „Kernstück des Siebten Rahmenprogramms“ (Europäische Kommission 2007). Für eine empirische Untersuchung der Performanzeffekte in EU-geförderten Rahmenprogrammen siehe u. a. Daniela Defazio et al. (2009); eine kritische Auseinandersetzung mit der EUForschungspolitik findet sich auch bei Nilgun Massih-Tehrani et al. (2015). 


\section{„Bologna“}

„Bologna“ schließlich, das dritte Reformvorhaben, stellt sich mit Blick auf Leistungsbewertungen, wie bereits angedeutet, anders dar als NPM und die „Exzellenzinitiative“. Auch der Einführung von NPM und der Etablierung der „Exzellenzinitiative“ lagen wissenschaftspolitische Einschätzungen zugrunde, die Qualitätsmängel von Lehre und Forschung an den deutschen Hochschulen diagnostizierten. Diese Einschätzungen blieben jedoch teils diffuser, teils partieller, als es dann bezüglich der Lehre in der „Bologna“-Erklärung geschah, die sich in Deutschland zunächst vor allem der Bund, dann aber auch die zuständigen Länderministerien zu eigen machten. In der universitären Forschung wollte man durch NPM die ,Guten“ und ,sehr Guten" - die es unbezweifelbar in größerer Anzahl gab - besser fördern und dafür den ,mäßigen“ Forschenden Ressourcen entziehen; und die „Exzellenzinitiative“ zielte auf einen spezifischen Typus großer Verbundforschung sowie auf - NPM unterstützende - universitäre Profilbildung in der Forschung. Hinsichtlich der Lehre könnte NPM ebenfalls wenn man die dafür adäquaten Leistungskriterien setzte, was allerdings weder einfach noch politisch vorrangig ist - das Lehrengagement sowie die Qualität stärken; faktisch hat man jedoch bis heute zumeist eher diejenigen Fächer und Universitäten belohnt, die große Studierendenzahlen aufwiesen. ${ }^{17}$ „Bologna“ setzte demgegenüber bei der Qualität der Lehre grundsätzlicher an. Die Studienreform stellte, in der Anwendung auf das deutsche Hochschulsystem, ein Generalverdikt gegen diejenigen Vorstellungen universitärer Bildung und darauf bezogener ,guter“ Lehre dar, die plakativ als Tradition „Humboldt“ von größeren Teilen der Professorenschaft hochgehalten wurden. In einer „Wissensgesellschaft", in der eine größere Mehrheit künftiger Generationen eine akademische Ausbildung benötige, die ihre „Employability“ erst sicherstelle, müsse das universitäre Studium - inhaltlich und strukturell - radikal umgestaltet werden (Serrano-Velarde 2009, S. 342-344). ${ }^{18}$ Bisherige Qualitätskriterien - so die

\footnotetext{
${ }^{17}$ Dies zeigt sich etwa daran, dass in die lehrbezogene LOM der Länder weitestgehend Belastungsfaktoren einfließen. Als Beispiel siehe etwa die aktuelle Niedersächsische Modellbeschreibung der Leistungsbezogenen Mittelzuweisung (Niedersächsisches Ministerium für Wissenschaft und Kultur o. J.).

${ }^{18}$ In der Bologna-Deklaration (1999 - Zitate: o. S.) spiegelt sich dieser Anspruch in der Betonung eines „Europa[s] des Wissens [...] als unerläßliche Voraussetzung für gesellschaftliche und menschliche Entwicklung“ wider. Dem europäischen Hochschulraum wird dabei eine Schlüsselrolle nicht nur in der Förderung der Mobilität, sondern gerade auch der ,,arbeitsmarktbezogenen Qualifizierung seiner Bürger“ zugeschrieben.
} 
nun in einer weder bei NPM noch bei der „Exzellenzinitiative“ gezeigten Überzeugung und Geschlossenheit der Hochschulpolitik - müssten zwar nicht zur Gänze abgeschafft, wohl aber sehr stark relativiert und in einen gänzlich neuen Bezugsrahmen gestellt werden. Bisherige Maßnahmen zur Qualitätssteigerung der Lehre wie etwa freiwillige oder auch verpflichtende Veranstaltungsevaluationen durch Studierende stellten sich vor diesem Hintergrund als viel zu schwach dar und bilden - vor allem in Relation zur externen Evaluation im Rahmen der Akkreditierung - in „Bologna“ nur noch ein untergeordnetes Instrument.

Anders gesagt, drückt sich in „Bologna“ das pauschalste Misstrauen der drei Reformen aus. Dem entspricht, dass hier nicht auf eine Inszenierung von Leistungskonkurrenz als Instrument der Qualitätsverbesserung gesetzt wird, sondern auf Leistungskontrolle gemäß einem hierarchisch gesetzten engen Reglement, wie fortan Studienziele und -gänge auszusehen haben. Die alten Studiengänge wurden per Dekret abgeschafft und durch neue ersetzt, ohne sich noch auf irgendwelche Diskussionen darüber einzulassen (Witte 2006, S. 149-206); und damit die neuen Studiengänge den jetzt geltenden hochschulpolitischen Vorstellungen ,guter' Lehre entsprechen und nicht unter der Hand wieder die bisherigen professoralen Vorstellungen ,eingeschmuggelt` werden, wurde - als achte Maßnahme der Leistungsbewertung - die bereits erwähnte regelmäßige Akkreditierung von Studiengängen vorgeschrieben. Es geht also, anders als bei den bisher geschilderten Maßnahmen, nicht um eine je individuelle Leistung hier: in der Lehre - und deren positive oder negative Sanktionierung, sondern um die grundsätzliche Leistungsfähigkeit von Studiengängen als kollektiv getragenen Aktivitäten.

Früher konzipierten Lehrende einen Studiengang, über dessen Etablierung in den Gremien der akademischen Selbstverwaltung - zumeist Fachbereichsrat und Senat - entschieden wurde und der dann im Ministerium nicht unter fachlichen oder didaktischen Gesichtspunkten, sondern nur noch mit Blick auf die Landeshochschulplanung sowie anhand von formellen, vor allem prüfungsrechtlichen Kriterien geprüft und genehmigt wurde. „Bologna“ enthält als wesentlichen Bestandteil die Etablierung eines Systems von Agenturen und Verfahren der inhaltlichen und didaktischen Bewertung aller Studiengänge gemäß festgelegten Kriterien, die überfachlich und überlokal gelten (Schade 2004; Serrano-Velarde 2008). Die Agenturen bedienen sich dabei - neben VertreterInnen der Berufspraxis und Studierenden als GutachterInnen - zwar der Expertise von FachkollegInnen, um in einem aufwendigen Verfahren Studiengänge detailliert $\mathrm{zu}$ beurteilen und gegebenenfalls verbindliche Auflagen oder fast immer Empfehlungen zur Überarbeitung eines Studiengangs 
zu formulieren. Die MitarbeiterInnen der Agenturen, die jede Begutachtungskommission betreuen, geben allerdings die Prüfkriterien detailliert vor und überwachen, dass jedes Kriterium beachtet wird. Zudem wurde erwartet, dass an den Universitäten Stellen und Organisationseinheiten aufgebaut wurden, die für das kontinuierliche Qualitätsmanagement, also die Überwachung und Optimierung der „Bologna“-Vorgaben, zuständig sind (Kloke 2014). Die mit dieser Gestaltung des Akkreditierungsverfahrens unausgesprochen, aber unmissverständlich kommunizierte Generaleinschätzung lautet: ProfessorInnen sind zumeist nicht fähig oder nicht willens, ohne Vorgaben und Ratschläge der Agenturen funktionstüchtige und den Ansprüchen der Berufswelt jenseits von Wissenschaftskarrieren genügende Studiengänge zu entwerfen und mit einer dauerhaft hohen Qualität der Lehre zu betreiben.

\subsection{Berufliche Identitätsbehauptung von ProfessorInnen}

Auch ohne in diesem kurzen Abriss der einschlägigen Strukturveränderungen durch NPM, „Exzellenzinitiative“ und „Bologna“ weiter ins Detail gehen zu müssen, deuten sich bereits Spannungsfelder zwischen diesen Veränderungsprozessen und dem beruflichen Selbstverständnis von ProfessorInnen an. Um eine theoretisch verankerte empirische Herangehensweise an solche Spannungsfelder vorzubereiten, entwerfen wir im Weiteren einen analytischen Bezugsrahmen zur beruflichen Identitätsbehauptung von ProfessorInnen.

Zunächst einmal ist unbestreitbar, dass die beschriebenen Strukturveränderungen wichtige Interessen von ProfessorInnen tangieren können. ProfessorInnen können beispielsweise keine Lust haben, ihre Lehre umstellen zu müssen, etwa auf einmal auch „Schlüsselqualifikationen“ statt nur fachliche Inhalte $\mathrm{zu}$ vermitteln, oder sich anstelle garantierter Grundausstattungsmittel in die Drittmittelkonkurrenz hineinzubegeben und dort immer wieder auch erfolglos zu sein. Diese und andere Veränderungen können Aufwand bedeuten, der einem umso unliebsamer ist, je weniger man von der sachlichen Berechtigung der betreffenden Maßnahmen überzeugt ist. Umgekehrt kann jemand auch bestimmte Reformmaßnahmen als förderlich für die eigene Interessenverfolgung ansehen. Wenn eine Professorin in ihren Forschungsaktivitäten ein High Performer ist, freut sie sich darüber, dass die W-Besoldung das mit Zulagen honoriert: Endlich begreift die Hochschulpolitik, dass die Professorin , alles richtig macht'!

Uns interessiert hier allerdings, jenseits der allgegenwärtigen Interessenlagen, eine tieferliegende Quelle des Unbehagens, aber womöglich auch der 
Freude, angesichts der Reformen. Wenn wir diejenigen Strukturveränderungen des deutschen Hochschulsystems, die sich auf Leistungsbewertungen beziehen, ins Zentrum unserer Aufmerksamkeit rücken, nehmen wir die PrincipalAgent-Betrachtungsweise zunächst einmal beim Wort - aber nicht, weil wir mit ihr übereinstimmen, sondern um umgekehrt ihren blinden Fleck herauszustellen. Wenn man, so wie diese Perspektive es tut, Individuen ausschließlich als interessengeleitete Akteure begreift, kann man nämlich überhaupt nicht bemerken, dass bestimmte Arten des Kontrollierens und Sanktionierens von Leistungen von denjenigen, die solchen Prozeduren unterworfen sind, als Missachtung eigener tätigkeitsbezogener Ansprüche und geradezu als demütigend empfunden werden können. Im Rahmen der Principal-Agent-Perspektive argumentierende VerfechterInnen der angesprochenen Reformmaßnahmen könnten argumentieren, man gehe als Prinzipal bzw. dessen Repräsentant ,realistisch“ davon aus, dass die Agenten eben - wie man selbst auch - eigeninteressiert seien und deren Eigeninteressen oft genug denen des Prinzipals zuwiderliefen, weshalb dessen berechtigte eigene Interessenverfolgung impliziere, die Agenten so zu beeinflussen, dass deren Interessen sich seinen annähern. Dass man sich so aber schnell als ,Elefant im Porzellanladen' aufführt, lässt sich - aus der Betroffenensicht eines Agenten - an einem Professor aus den Naturwissenschaften illustrieren, der in einem Interview schildert, wie er die Akkreditierung neuer Studiengänge, an denen er beteiligt war, durch die Akkreditierungsagenturen und deren Kommissionen erlebt hat. Er berichtet u. a.:

\begin{abstract}
„Die Begutachtung [...] fand ich zumindest grenzwertig. Es kamen fünf Profs von dieser Agentur und haben uns behandelt wie die Schulkinder. Im Grunde haben sie sich selbst disqualifiziert. Das wichtigste Anliegen eines dieser Gutachter war die Frage, ob sein eigenes Lehrbuch hier verwendet würde. Wenn man auf dem Niveau diskutiert, kann eigentlich nicht mehr viel Gutes dabei herauskommen. Das Auftreten dieser Kommission war überhaupt nicht angemessen." (zitiert in Kaufmann 2012, S. 205)
\end{abstract}

Der Interviewte ist immer noch zutiefst empört. Das zeigt sich nicht zuletzt daran, wie oft er sozusagen verbal nachtritt: von „grenzwertig“ und „Profs“ bis zu „überhaupt nicht angemessen“. Was immer tatsächlich bei der geschilderten Begebenheit vorgefallen ist, und welche Interessenlagen aufseiten dieses Professors im Spiel gewesen sein mögen: Viel wichtiger ist für ihn, dass er sich in seiner beruflichen Identität zutiefst verletzt fühlt. Man wurde ,behandelt wie die Schulkinder" - und das ausgerechnet auch noch von Fachkollegen! Nicht mal auf deren Unterstützung kann man sich mehr verlassen! Sie kamen „von dieser Agentur“ und hatten - bereits dadurch - „,ich selbst disqualifiziert“. Derjenige, 
der sich erkundigte, ob sein Lehrbuch Verwendung finde, setzte dem Ganzen nur die Krone auf. Selbst wenn er sich hinsichtlich eines von jemand anderem verfassten Lehrbuchs erkundigt hätte, wäre der Befragte wohl ähnlich indigniert gewesen.

Individuen - hier in der Berufsrolle des Professors - sind also nicht nur interessengeleitete, sondern auch identitätsgesteuerte Akteure, die sich an evaluativen und normativen Selbstansprüchen ausrichten: Welchem Selbstbild strebe ich nach? Wer will ich werden, und wie soll ich sein? Ausgehend von dieser Prämisse wollen wir die Auseinandersetzungen über die Reformmaßnahmen im deutschen Hochschulsystem hier nicht als Interessenkonflikte, was sie wohlgemerkt stets auch sind, sondern als Identitätskonflikte verstehen. ${ }^{19}$ Interessenkonflikte sind ,teilbare Konflikte“, in denen je nach Kräfteverhältnis Kompromisse gefunden werden können, während Identitätskonflikte „unteilbar“ in dem Sinne sind, dass es um starke Überzeugungen geht, auf denen man - im Extremfall um den Preis des eigenen Lebens - beharrt. ${ }^{20}$ Kompromisse zu machen wäre hier Verrat.

\section{Forschungsstand}

Nur ganz kurz gehen wir auf den Forschungsstand zu dieser Thematik ein. Einige Stichworte zu einschlägigen Forschungsrichtungen können hier genügen, weil wir die von uns aufgegriffenen Konzepte und Befunde dieser Forschungen später jeweils dort mit ansprechen, wo sie unsere eigenen empirischen Ergebnisse und theoretischen Interpretationen bestätigen, ergänzen, aber ihnen vielleicht auch hier und da widersprechen. Generell ist zu sagen, dass die Forschungslage kein abgerundetes Bild ergibt, sondern kleinere oder größere Teilausschnitte mal ausgiebiger, mal nur lückenhaft untersucht worden sind.

Die Professionssoziologie hat sich schon seit langem immer wieder mit dem komplizierten Verhältnis von Profession und Organisation beschäftigt (Scott

\footnotetext{
${ }^{19}$ Aus einer Anerkennungsperspektive verweist Stephan Voswinkel (2011) auf die enge Verbindung von tätigkeitsbezogenen Ansprüchen der Beschäftigten und dem Kampf um Anerkennung dieser so zum Ausdruck gebrachten Identitäten. Die Beziehung zwischen Beschäftigen und Arbeitgebern ist daher nicht nur als Interessen-, sondern auch als eine Anerkennungsbeziehung zu denken. Entsprechend plädiert Voswinkel dafür, Anerkennung und Interesse nicht als alternative Konzepte, sondern zwei einander ergänzende Perspektiven auf Arbeitsverhältnissezu behandeln.

${ }^{20}$ Siehe Vilhelm Aubert (1963) zur Unterscheidung von „conflicts of interest“ und „,conflicts of values or beliefs“ sowie Albert Hirschman (1994) zur Unterscheidung ,teilbarer" und „,unteilbarer Konflikte“.
} 
1966; Etzioni 1969a, 1969b; Mintzberg 1979, S. 348-379; Meier und Schimank 2012, S. 61-76; Noordegraaf 2007, 2015; Evetts 2013). Mit Blick auf NPM ist diese Sicht so zugespitzt worden, dass die Forcierung der geschilderten Strukturveränderungen zu einer De-Professionalisierung, etwa auch von ProfessorInnen, führe (Lohr et al. 2013a; Schimank 2015).

Die in den letzten Jahren aufgekommene Soziologie der Bewertung (Lamont 2012; Meier et al. 2016; Nicolae et al. 2019) begreift Bewertungsprozesse als allgegenwärtiges soziales Phänomen und untersucht hiervon ausgehend Prozesse und Praktiken des Kategorisierens, Vergleichens und Bewertens in verschiedenen Lebensbereichen. Auch Hochschulen gehören zu ihrem empirischen Gegenstand. Dabei wurde u. a. auf die disziplinierenden Wirkungen und Anpassungseffekte von Bewertungen hingewiesen. Hochschulen passen sich etwa an Bewertungskriterien öffentlichkeitswirksamer Rankings an (für die US-amerikanischen Law Schools: Espeland und Sauder 2007, 2016; Sauder und Espeland 2009), weshalb solche Vergleichsinstrumente nicht nur mehr oder weniger adäquate Abbildungen der Realität darstellen, sondern diese auch formen, wenn Universitäten sich ,an der Beobachtung des Beobachtetwerdens orientieren“ (Heintz 2008, S. 122).

Forschungen über Subjektformen in der Moderne und in der gegenwärtigen ,neoliberalen“ Ära wie die oft an Michel Foucault anschließenden Gouvernmentality Studies haben sich neben allgemeinen Charakterisierungen des zeitgenössischen „unternehmerischen Selbst“ (Bröckling 2007) ${ }^{21}$ u. a. auch fallstudienartig mit Universitäten und ProfessorInnen, vor allem im angelsächsischen Raum, beschäftigt (z. B. Shore 2008; Peter 2010). Oft bleibt es jedoch bei der Analyse von Diskursen (Draheim 2012; Wetzel 2013; Bröckling und Peter 2017), also „talk“; wie sich im Verhältnis dazu die Handlungspraktiken darstellen, ist unklar oder wird allenfalls mit anekdotischer Evidenz erwähnt.

Axel Honneth $(1992,2010)$ hat in einem groß angelegten sozialphilosophischen Entwurf Georg Wilhelm Friedrich Hegels und George Herbert Meads Vorstellungen über Subjektivität zu einer Theorie gesellschaftlicher Anerkennungsordnungen zusammengeführt. Die vorgeschlagene Konzeptualisierung von Gesellschaft als ein aus drei Teilordnungen - Anerkennung als Liebe, als Recht und als Solidarität - bestehendes Gebilde ist unterkomplex und für unsere Zwecke wenig hilfreich; die mikrosoziologischen Überlegungen zu Interaktionsdynamiken von Anerkennung und Missachtung gehen hingegen an

\footnotetext{
${ }^{21}$ Siehe ferner viele Beobachtungen im „Glossar der Gegenwart“ (Bröckling et al. 2004).
} 
vielen Stellen in die gleiche Richtung wie unsere identitätstheoretisch fundierte Perspektive.

Anknüpfend an Honneth hat sich die Arbeits- und Industriesoziologie mit Anerkennung in zeitgenössischen Arbeits- und Berufsverhältnissen beschäftigt und dabei eine breite Spanne von Tätigkeiten und Organisationen fallstudienartig in den Blick genommen (Holtgrewe et al. 2000; Voswinkel 2001; Honneth et al. 2012; Voswinkel und Wagner 2012; Flecker et al. 2014; Dammayr 2019). Da dem NPM vergleichbare Strukturveränderungen auch in anderen Teilen des öffentlichen Sektors - Krankenhäusern, öffentlicher Verwaltung, teilprivatisierten, ehemals staatlichen Unternehmen wie Bahn oder Post - sowie in Unternehmen implementiert worden sind, stoßen diese Studien vielfach auf ähnliche Phänomene wie die uns hier interessierenden.

Ein u. a. aus den Critical Labour Studies heraus entstandenes, mittlerweile relativ eigenständiges Forschungsfeld sind die Resistance Studies (Courpasson und Vallas 2016), die sich u. a. auch mit dem aus Forschungen über Organisationswandel bekannten ,resistance to change“ befassen (Ybema et al. 2016). Teilweise werden diese speziell auf NPM bezogen (z. B. Thomas und Davies 2005). Auch hier finden sich gute Beobachtungen, die den Blick für bestimmte Aspekte des Verhältnisses von Hochschulen und ProfessorInnen schärfen.

Innerhalb der Arbeits- und Berufssoziologie setzen sich einige Arbeiten explizit mit den Arbeitsbedingungen von WissenschaftlerInnen und Wissenschaftskarrieren auseinander und stellen diese nicht zuletzt in den Kontext der Reformen (Funken et al. 2015; Matthies 2016; für den wissenschaftlichen Nachwuchs: Rogge 2017; Gassmann 2018). Dabei interessiert auch, wie sich die an den Universitäten bestehenden Arbeitsbedingungen und Beschäftigungspolitiken auf die Lebens- und Karriereplanungen der Beschäftigten auswirken. Einige der Befunde lenken den Blick auf bestimmte Problemlagen oder Möglichkeiten, die für unsere Fragestellung von Belang sind.

In diesem Zusammenhang kann auch die Geschlechterforschung angeführt werden, die sich ähnlich gelagerten Fragen, vor allem unter dem Aspekt etwaiger Geschlechterdifferenzen, widmet (Zimmermann et al. 2008; Binner et al. 2013; Riegraf 2018; Binner und Weber 2019). Die Studien nehmen das Verhältnis von Geschlecht und „unternehmerischer“ Universität kritisch in den Blick, stellen dann aber u. a. fest, dass NPM oder die „Exzellenzinitiative“ unter bestimmten Bedingungen die Gleichstellung von Frauen auch befördern können.

Schließlich gibt es in den Higher Education Studies, vor allem in Großbritannien und anderen angelsächsischen Ländern, Fallstudien und Erfahrungsberichte zu Verletzungen der ,academic identity“ (Henkel 2000, 2005; 
Henkel und Vabo 2006; Barry et al. 2001; Clegg 2008; für Finnland Ylijoki 2003, 2014) und zu „micro-resistance“ von WissenschaftlerInnen an Universitäten (Anderson 2008; Teelken 2012). Für Deutschland ist hier weitgehend Fehlanzeige zu vermelden (einige Beobachtungen bei Kaufmann 2012; Lohr et al. 2013b; Flink und Simon 2014), sieht man von den im Kap. 2 zur Sprache kommenden, oft sehr meinungsstarken - sprich: empörten - Beiträgen von ProfessorInnen zum medialen Diskurs ab. Der Tenor dieser Meinungsäußerungen ist unverkennbar kein rein interessenpolitischer; man sorgt sich vielmehr um das Ethos der Wissenschaft, den ProfessorInnenberuf und die Qualität von Forschung und Lehre.

Ein weiterer, methodisch aber anders ausgerichteter, da vor allem auf standardisierten Befragungen basierender Zweig innerhalb der Higher Education Studies befasst sich wiederum in auch international vergleichender Perspektive mit den Arbeitsbedingungen und der Arbeitszufriedenheit der ProfessorInnen. $\mathrm{Zu}$ nennen sind hier vor allem die länderübergreifenden Hochschullehrerbefragungen wie die „Carnegie Study on the Academic Profession“ zu Beginn der 1990er Jahre und die Folgestudie zur „Changing Academic Profession“ (Shin et al. 2014) und deren deutsche Teilstudien (Enders und Teichler 1995; Jacob und Teichler 2011; Teichler 2014). Diese in unregelmäßigen Abständen, aber wiederholt durchgeführten Befragungen zu Arbeitsbelastungen, -inhalten und -zufriedenheit der ProfessorInnen zeigen Veränderungen auf, die gewollte und ungewollte Effekte der angesprochenen Reformen sein können.

Die aufgelisteten Forschungsperspektiven eint, dass das Verhältnis zwischen der beruflichen Identität von Organisationsmitgliedern auf der einen, Organisationsveränderungen auf der anderen Seite vor allem daraufhin betrachtet wird, wo es problematisch für die Identität wird oder zu werden droht. Die meisten Perspektiven gehen darüber hinaus davon aus, dass solche Identitätsprobleme generierende Organisationsveränderungen heute in vielen Arbeitsorganisationen stattgefunden haben, und oft wird dabei für den öffentlichen Sektor explizit auf NPM verwiesen. Auch wenn wir in unseren empirischen Befunden ebenfalls vielfach auf Identitätsbedrohungen gestoßen sind, halten wir unsere Analyseperspektive jedoch bewusst offen dafür, dass dieselben Organisationsveränderungen möglicherweise für einige ProfessorInnen auch Identitätschancen enthalten, die ergriffen worden sind.

\section{Professorale Identität}

Um bestimmen zu können, welche Strukturveränderungen wie als Identitätsbedrohungen oder Identitätschancen wirken können, muss zunächst genauer umschrieben werden, aus welchen evaluativen und normativen Selbstansprüchen sich die professorale Identität zusammensetzt. In einem idealtypisch stilisierten 
Rollenmuster, das in Reinform längst nicht bei jeder konkreten Person vorliegt und von dem es mehrere, hier vorerst nur angedeutete, empirisch häufiger vorkommende partielle Abweichungen gibt, kann man hypothetisch drei große Komponenten professoraler Identität annehmen. ${ }^{22}$ Die ersten beiden beziehen sich auf die zwei zentralen beruflichen Tätigkeiten der Forschung und der Lehre, die dritte Komponente formuliert eine für beide Tätigkeitsfelder sowie für die Berufsrolle insgesamt konstitutive Voraussetzung. ${ }^{23}$

Gemäß dem in der ProfessorInnenrolle verankerten Forschungsethos wird wissenschaftliches Erkenntnisstreben von einer „curiositas“-Orientierung geleitet, sucht also Wahrheit um ihrer selbst willen jenseits aller außerwissenschaftlichen Nutzenerwägungen. Dieses primäre Verständnis dessen, was wissenschaftliche Forschung an Universitäten ausmacht, kann sich mit einem gesellschaftlichen Auftrag als sekundärer Verpflichtung verbinden. Eine Teilgruppe der ProfessorInnen sieht sich auch als Sachwalter des Gemeinwohls - z. B. als ForscherInnen, die zur Heilung von Krankheiten, zur technischen Verbesserung der Lebensbedingungen oder zur Reflexion gesellschaftlicher Probleme wie Fremdenfeindlichkeit beitragen wollen. Ob nur „curiositas“ oder zusätzlich auch Gemeinwohl: Zur ProfessorInnenrolle gehört ökonomisches Desinteresse. Anders als UnternehmerInnen will man durch die Berufsausübung nicht vor allem reich werden; wenn man sein Einkommen oder Vermögen mehrt, geschieht dies sozusagen nur als Kollateralnutzen wissenschaftlichen Erkenntnisstrebens.

Das Lehrethos, das die ProfessorInnenrolle vermittelt, fokussiert sich auf Bildung durch forschungsbasierte Lehre - die berühmte „Einheit von Forschung

\footnotetext{
${ }^{22}$ Dieses Muster hat analytisch denselben Status wie Robert Mertons (1942) bekanntes, aber oft missverstandenes Bündel von das ,scientific ethos“ definierenden Prinzipien, das John Ziman (2000) einer aktualisierenden Überprüfung unterzog. Es geht dabei nicht um Beschreibungen der realen Praxis, die mehr oder weniger anders sein kann - schon gar nicht geht es um normative Vorstellungen, die wir als wissenschaftliche BeobachterInnen an diese Praxis richten. Sondern es handelt sich um empirisch festmachbare Selbstansprüche derer, die Wissenschaft betreiben - wobei sie sich darüber im Klaren sind, dass niemand diesen Selbstansprüchen immer und manche ihnen niemals gerecht werden, die Selbstansprüche also einen erwünschten fordernden Charakter haben.

${ }^{23}$ Der Deutsche Hochschulverband hat diese professorale Identität sehr viel ausführlicher und differenzierter, doch in der Stoßrichtung mit dem hier vorgestellten analytischen Konstrukt übereinstimmend, in einer programmatischen Selbstverständnis-Erklärung niedergelegt (DHV 1991). Dieses Dokument ist zwar schon etwas älter, dürfte aber in den meisten Punkten in der Professorenschaft - nicht nur der deutschen - nach wie eine Mehrheit finden.
} 
und Lehre“. Die Betonung von zweckfreier Bildung ist als Zurückweisung von instrumentell ausgerichteter Ausbildung zu verstehen. Auch wenn das in Fächern wie den Rechts-, Wirtschafts- oder Ingenieurwissenschaften sowie der Medizin immer schon entweder anders gesehen wurde oder eine Lebenslüge war: UniversitätsprofessorInnen, in Abgrenzung zu ihren FachhochschulkollegInnen, verstehen ihre Lehre nicht als berufsbefähigend. Berufsbefähigung soll vielmehr wiederum nur ein - durchaus reklamierter - Kollateralnutzen forschungsbasierter Lehre sein. Zugleich sehen sich UniversitätsprofessorInnen nicht als LehrerInnen, weisen also ein Verständnis der Universität als Fortsetzung von Schule strikt zurück. Dem liegt eine Auffassung von Studium zugrunde, der gemäß dieses wesentlich kein didaktisch fremdunterstütztes Lernen sein soll. Universitäre Bildung ist vielmehr das Ergebnis von Selbstlernen auch anhand spröder, gar abweisender Lernstoffe in einer Gemeinschaft von Lehrenden und Lernenden.

Um dieses Forschungs- und Lehrethos ausleben zu können, bedarf es einer hochgradigen individuellen Autonomie als ermöglichender Identitätskomponente. Autonomie bedeutet nicht Autarkie im Sinne eines überhaupt nicht extern beeinflussten und sich selbst genügsamen Handelns - jedoch ein Handeln, das externe Einwirkungen nach eigenen Gesichtspunkten verarbeitet, also Selbstbestimmung als dominanten Handlungsmodus hat. Dies erstreckt sich als Anspruch auf alle Facetten von Forschung - von der Themenwahl über die Wahl theoretischer und empirischer Herangehensweisen bis hin zur Wahl von Publikationsformaten (Gläser und Schimank 2014). Bei der Lehre ist zwar entsprechend der Denomination der Professur ein thematischer Rahmen abgesteckt; innerhalb dessen gilt aber die möglichst autonome Festlegung aller weiteren inhaltlichen, didaktischen und prüfungstechnischen Modalitäten. Eingebettet ist diese individuelle Autonomie in die beanspruchte kollektive Autonomie der Scientific Community als kognitiver Gemeinschaft derer, die zum gleichen Themenspektrum Beiträge zum Erkenntnisfortschritt liefern (Gläser 2006; Gläser und Lange 2007). Organisatorisch abgesichert sind individuelle und kollektive Autonomie durch die Dominanz der Professorenschaft als Statusgruppe in der "Gruppenuniversität" - umso mehr, je stärker Belange von Forschung und Lehre berührt sind (Zechlin 2017). Ein hohes Berufsprestige der Professorenschaft, wie es in vielen westlichen Gesellschaften und auch Deutschland gegeben ist, bedeutet eine zusätzliche Anerkennung dieser Autonomieansprüche.

\section{Identitätsbedrohungen}

Vor dem Hintergrund dieser vermuteten Identitätskonstruktion kann man nun fragen, wie sich die geschilderten Strukturveränderungen ausgewirkt haben könnten. In bisherigen Studien ebenso wie in Selbsterfahrungsberichten von 
ProfessorInnen dominieren Schilderungen von Identitätsbedrohungen durch neue Maßnahmen der Leistungsbewertung. Im Einzelnen können explorativ auf der Grundlage anderer Studien und eigener Vorüberlegungen fünf Arten der Identitätsbedrohung genauer ausgemacht werden - also Erschütterungen des Selbstanspruchs einer Professorin oder eines Professors, selbstbestimmt, gute` Lehre und Forschung zu betrieben.

Die erste Art dieser Identitätsbedrohung kam bereits in der zitierten Äußerung eines Professors zur Akkreditierung eines Studiengangs, den er mitträgt, zum Ausdruck: das wahrgenommene Unwissen und Desinteresse von Bewertungsinstanzen. Denn sie wissen nicht, was sie tun - und es ist ihnen auch egal: Auf eine solche Einschätzung lässt sich diese Identitätsbedrohung aufseiten der davon Betroffenen bringen: Man muss sich gefallen lassen, von ,Ignoranten' und ,Desinteressierten " bewertet zu werden. Was die Leistungsbewertungen bewirken können, ist den Bewertenden - so die Einschätzung - nicht klar; und es ist ihnen genauso wenig klar, dass ihnen das nicht klar ist: ein „unknown unknown“ im Sinne Donald Rumsfelds.

Eine zweite Quelle von Identitätsbedrohungen stellen inadäquate Bewertungskriterien - in den Augen der ProfessorInnen - dar. Inadäquanz kann sich dabei auf Verschiedenes beziehen: Kriterienlisten können unvollständig sein, also von den ProfessorInnen für wichtig gehaltene Tätigkeitsdimensionen nicht enthalten; es können umgekehrt Kriterien angelegt werden, die als unpassend erachtet werden; Kriterien können zu stark oder zu gering gewichtet werden; und Kriterien können falsch oder zu partiell operationalisiert werden, wenn beispielsweise die Förderung des wissenschaftlichen Nachwuchses nur als Mitwirkung an Graduiertenkollegs verstanden wird und die Individualbetreuung von DoktorandInnen unter den Tisch fällt. Wohin dies aus Sicht eines Professors, der selbst in der C-Besoldung geblieben ist, führen könne, sieht er am Beispiel einiger jüngerer KollegInnen in der leistungsbezogenen W-Besoldung bestätigt, deren Verhalten er dahin gehend kritisiert: „Die [...] gehen nicht mehr in die Uni und sagen sich, , was mache ich in Forschung und Lehre', sondern die sagen, ,wie komme ich heute auf meine Punkte?““ (zitiert bei Flink und Simon 2014, S. 137). Neben negativen Folgen für die Wissenschaft durch diese Leistungsbewertungen wird also auch ein beschämender persönlicher Opportunismus als Effekt attestiert. Das ,Fremdschämen' für die ,Identitätsverbiegung ' der anderen - die das ja oft nicht einmal mehr merken - kann im Übrigen die größere Identitätsbedrohung sein.

Drittens kann man als Identitätsbedrohung erleben, wenn man sich durch Kriterien und Verfahren der Leistungsbeurteilung zur Missachtung der sachlichen Erfordernisse von Forschung oder Lehre gezwungen sieht. Man wird zur 
,schlechten ' Arbeit genötigt, und ,gute' Arbeit zahlt sich nicht aus, sondern wird sogar bestraft, weil eine große Kluft zwischen fachlichen - sachangemessenen - und organisational zählenden Gesichtspunkten besteht. In diese Richtung verweisen nicht zuletzt die empörten Äußerungen vieler ProfessorInnen in F\&L zur Überbetonung der - von der Organisation besonders erwünschten und geförderten - kooperativen Forschungsvorhaben. Ein anderer Stein des Anstoßes: wenn Forschungsergebnisse zunehmend in kleinste Häppchen zerlegt werden müssen, weil nur mehr Zeitschriftenartikel zählen und Monografien in den organisationalen Punkte- und Bewertungssystemen keinen angemessenen Stellenwert besitzen.

Die vierte Art der Identitätsbedrohung, die aus Leistungsbewertungen hervorgehen kann, besteht in einer auferlegten Zweck-Mittel-Verkehrung. Eigentlich sollte es nach Einschätzung vieler ProfessorInnen so sein, dass Zweck ihres Tuns in der Forschung Erkenntnisfortschritt ist; und je nachdem kann die Einwerbung von Drittmitteln ein Mittel dazu sein, diesen Zweck verfolgen zu können. Nun aber gilt, durch Leistungsbewertungen unterstrichen: Man muss Drittmittel ,reinholen " und die Forschungsziele daraufhin ausrichten. Das Einwerben von Drittmitteln wird, mit welchen Konsequenzen auch immer für die Forschung, auf die Spitze getrieben, weil es vor allem darum geht, Forschung zu betreiben, um Geld für den unterfinanzierten Haushalt der eigenen Universität verdienen zu müssen. Dieser organisationalen Zumutung erwehrte sich Niklas Luhmann (1997, S. 11) noch mit seiner bekannten, sowohl süffisant-trotzigen als auch melancholischen Bemerkung: „Mein Projekt lautete damals und seitdem: Theorie der Gesellschaft; Laufzeit: 30 Jahre; Kosten: keine.“ Allein, dass er als „Kosten“ benennt, was Universitätsleitungen schon seit langem als vorzeigbare Einnahmen verbuchen, spricht Bände; und sogar ein Luhmann hätte es heute wohl schwerer, sich dem Geldverdienen für die eigene Organisation zu entziehen.

Die fünfte Art von Identitätsbedrohung, die von Leistungsbewertungen ausgehen kann, ist der sich einstellende generelle Eindruck, dass einem permanent auf die Finger geschaut und nicht über den Weg getraut wird - also die schon angesprochene, dem Principal-Agent-Modell gewissermaßen inhärente Kultur des Misstrauens. ProfessorInnen fühlen sich von ihrer Organisation pauschal verdächtigt, faul zu sein, sich hauptsächlich lukrativen Nebengeschäften zu widmen oder wissenschaftlichen Privathobbies zu frönen. Eine Professorin schildert anschaulich, wie das ihre Selbsteinschätzung erschüttert:

„Ich halte mich für eine sehr engagierte Professorin [...] [Auslassung im Original] ich hatte mir eingebildet, das steuert mich nicht, weil ich sage, ich lasse mir doch nicht von so einem System vorschreiben, wie ich meine Professur ausgestalte, aber 
wenn ich das nicht mache, merke ich, es kränkt mich, dass die Gefahr besteht, dass ich nicht mal $[\mathrm{x}]$ Punkte zusammenkriege, obwohl ich ein aufregendes, tolles und relevantes Jahr für meine Studenten und auch für mich und meine Entwicklung hatte und ich [x] Mitarbeiter gut vorangebracht habe." (zitiert bei Flink und Simon 2014, S. 139)

Diese fünf Arten der Identitätsbedrohung stellen eine induktiv gewonnene Auflistung ohne Vollständigkeitsanspruch dar, die sich allerdings auch in unserem empirischen Material als die zentralen Formen der Identitätsbedrohungen erweisen werden. Wichtig wird jedoch auch sein, das Ausmaß, in dem die berufliche Identität von ProfessorInnen bedroht ist, $\mathrm{zu}$ eruieren. Handelt es sich um massive und sich häufende Infragestellungen dessen, was jemand an Vorstellungen über, gute' Lehre und Forschung sowie an dafür benötigter Autonomie hat, oder geht es nur um vereinzelte Erlebnisse? Und stehen daneben durchaus noch Zufriedenheits- und Erfolgserlebnisse einschließlich der sozialen Anerkennung, die man vonseiten der Peers, der Studierenden, aber auch der eigenen Organisation erfährt?

Zugleich müssen wir die Augen offen halten für Identitätschancen, die sich aus den durch die Reformen hervorgebrachten Strukturveränderungen ergeben könnten. Zum einen erscheint es plausibel, dass sich diejenigen, die sich durch - gemessen an den angelegten Kriterien - sehr gute Forschungs- und Lehrleistungen auszeichnen, durchaus mit den neu etablierten Leistungsbewertungen anfreunden können. Denn sie sind ja die GewinnerInnen - und zwar nicht nur hinsichtlich der Befriedigung von Ressourcen- und Einkommensinteressen, sondern auch mit Blick auf soziale Anerkennung ihrer Leistungen. Zum anderen fanden Tim Flink und Dagmar Simon (2014, S. 136/137) in ihrer Untersuchung eine Teilgruppe von ProfessorInnen, die in Leistungsbewertungen keinerlei Identitätsbedrohung sehen, sondern ganz im Gegenteil „Leistungsbewertung als sportlichen Wettkampf" deuten, in dem man sich durch Erfolge Identitätsbestätigungen verschaffen kann. So äußert sich etwa jemand wie folgt:

„Ich finde schon, dass es Anreize geben soll und kann, weil diejenigen, die klasse Sachen machen, auch anerkannt sein sollen [...] [Auslassung im Original] Dieses Schneller, Weiter, Höher, diese Leistungsmentalität oder die negativen Seiten davon, im Grundsatz wäre das unserer intrinsischen Motivation nicht feindlich. Man will ja, man freut sich ja." (zitiert bei Flink und Simon 2014, S. 136)

Das muss nicht nur die Weltsicht derer sein, die schon als GewinnerInnen feststehen. Ein weiterer Befragter sieht sich durchaus auch längerfristig nicht auf dem Siegertreppchen und will den Wettkampf dennoch nicht missen - vor allem als Wettkampf mit sich selbst: 


\begin{abstract}
„Natürlich bin ich realistisch genug zu sehen, okay, ich werde vielleicht nie und auch nicht in den nächsten drei Jahren, wenn ich hier anfange, bei den Besten sein, ich will aber auch nicht bei den Schlechtesten sein, und da ist ein gewisser Sportsgeist, nicht in dem Sinne, dass ich den einen oder anderen Kollegen übertrumpfen will [...], aber natürlich orientiert man sich da, wo man steht, und freut sich, wenn man in den Leistungsparametern besser wird." (zitiert bei Flink und Simon 2014, S. 136)
\end{abstract}

Zusammen mit der Vermutung, dass kaum jemand in diesem nach wie vor privilegierten Berufsstand sich völlig resignativ als hilfloses Opfer von Leistungsbewertungen ansehen dürfte, verweisen solche Fälle darauf, dass es eine erhebliche Varianz der subjektiven Erfahrungen von Leistungsbewertungen gibt. Das kann zum einen daran liegen, dass die Art und Weise, wie die Strukturveränderungen je lokal umgesetzt werden, sich erheblich unterscheidet (Bogumil et al. 2013, S. 129-188). Zum anderen könnten aber auch disziplinäre Unterschiede sowie unterschiedliche Karrierephasen, in denen sich ProfessorInnen befinden, eine wichtige Rolle dabei spielen, wie jemand den Strukturveränderungen ausgesetzt und mit ihnen umzugehen in der Lage ist.

\title{
Identitätsbehauptung
}

Damit sind die professorale Identität und die Identitätsbedrohungen sowie Identitätschancen, die aus den eingeführten Leistungsbewertungen im deutschen Hochschulsystem erwachsen können, als analytisches Beobachtungsschema unserer empirischen Studie skizziert. Nun muss noch die Frage beantwortet werden, wie sich Identitätsbedrohungen oder -chancen auf eine gegebene berufliche Identität auswirken können. Hier lassen sich empirisch bewährte generelle Aussagen der soziologischen und sozialpsychologischen Identitätsforschung $\mathrm{zu}$ einem theoretischen Modell von Lebensführung als Identitätsbehauptung verknüpfen. ${ }^{24}$

Bis hierher haben wir die Identität einer Person als evaluative und normative Selbstansprüche bestimmt, also als Zusammenhang von Wollens- und SollensVorstellungen: Ich will eine bestimmte Art von Person mit einer bestimmten Lebensweise sein - und dies im Rahmen bestimmter Sollensvorgaben wie

\footnotetext{
${ }^{24}$ Lebensführung umfasst freilich noch vieles andere - hier interessiert uns nur die berufliche Lebensführung unter dem Gesichtspunkt der Identitätsbehauptung. Für ein vor allem an Erving Goffman (1963), den Pragmatismus und Symbolischen Interaktionismus (Strauss 1959) sowie sozialpsychogische Studien (Laing 1961; Gergen 1971) anknüpfendes soziologisches Modell der Identitätsbehauptung von Akteuren siehe Schimank (1981, S. 13-20, 2000, S. 121-143; für ProfessorInnen: Schimank 2014). Aktuelle Überblicke geben Peter J. Burke und Jan E. Stets (2009) sowie Alicia Cast und Stets (2016).
} 
z. B. dem Gebot, mein persönliches Fortkommen nicht auf Kosten anderer zu betreiben. Diese Selbstansprüche werden anhand kognitiver Selbsteinschätzungen kontrolliert: Bin ich so, wie ich sein will und soll - wie weit bin ich davon entfernt - und kann ich, realistisch betrachtet, so bleiben bzw. werden? Diese Fragen kann jemand nicht im Selbstgespräch beantworten. Eine Identität lässt sich nicht solipsistisch behaupten, sondern bedarf der Identitätsdarstellung vor Anderen und einer daraus resultierenden kontinuierlichen sozialen Bestätigung durch diese. Andere Personen, mit denen jemand soziale Beziehungen unterhält, sind mit ihren Reaktionen auf seine Identitätsdarstellung die Spiegel, in denen der Betreffende sich selbst erkennt. Wenn diese Spiegel ihn so wiedergeben, wie er sich selbst sieht, vermag er an seinen Selbstansprüchen festzuhalten. Seine Identität wird bestätigt. ${ }^{25}$ In dem Maße aber, in dem die Spiegel ihm ein ganz anderes Bild zeigen, kommen bei ihm Zweifel am Selbstbild - also Identitätsbedrohungen - auf.

Identitätsbestätigungen müssen nicht explizit als solche artikuliert werden. Damit eine Professorin weiß, dass sie ,gute" Arbeit leistet, bedarf es keiner ständigen Lobpreisungen. Als Minimum reicht aus, dass es keine Artikulationen größerer Zweifel an ihrer Arbeit gibt - etwa als Wegbleiben von Studierenden in ihren Vorlesungen oder als Ignorieren ihrer Veröffentlichungen. Solange alles ,in Ordnung ' ist, finden soziale Bestätigungen von Identitätsansprüchen überwiegend beiläufig statt. Wenn soziale Bestätigungen sich bis zu begeistertem Applaus - in Gestalt von bewilligten Projektanträgen, angenommenen Zeitschriftenartikeln, angefragten Keynote Speeches, positiven Lehrevaluationen, Rufen auf Professuren oder Forschungs- und Lehrpreisen etc. - steigern, eröffnen sich Identitätschancen: Die Identitätsansprüche können noch höher gesteckt werden.

Das ist die Steigerungsdynamik der Identitätsbehauptung: Ein Selbstbild wird kontinuierlich bestätigt und kann sich so immer weiter festigen und entfalten. Dem steht als entgegengesetzte Trajektorie eine Abwärtsdynamik gegenüber: Identitätsbedrohungen häufen sich. Dann sind soziale Bestätigungen umso wichtiger. Solange sie ausreichen, kann eine bedrohte Identität dennoch aufrechterhalten werden; hierfür sind dann allerdings nicht mehr nur sich beiläufig einstellende soziale Bestätigungen, sondern durch Praktiken der Identitätsbehauptung sozusagen eingeholte Identitätsbestätigungen wichtig. Dann wird durch „resistance“ gegen die Identitätsbedrohungen Identität , ausgeflaggt" - entweder als manifester oder als latenter Konflikt zwischen Identitäts-

\footnotetext{
${ }^{25}$ Bestätigung muss nicht Gutheißen bedeuten: Eine Terroristin kann sich als Kämpferin für die ,gerechte Sache " auch dadurch bestätigt sehen, dass sie von den ,Feinden “ als abscheuliche Mörderin eingestuft wird.
} 
ansprüchen und Strukturveränderungen. ProfessorInnen trumpfen rhetorisch auf oder riskieren den Konflikt, z. B. mit ihren Universitätsleitungen, und können selbst eine Niederlage in der Sache ,erhobenen Hauptes' als persönliche Identitätsbehauptung erfahren; oder sie artikulieren ihre nicht aufgegebenen Identitätsansprüche ,klammheimlich' oder in Nischen durch verschiedene Arten von „micro-resistance“ (Anderson 2008) und bekommen dafür Anerkennung durch KollegInnen. Wenn die Identitätsbehauptung freilich auf Dauer zu schwach gegenüber den Identitätsbedrohungen ist, findet früher oder später eine aufgezwungene Identitätsanpassung statt. Das wird manchmal euphemistisch als ,Lernen' umschrieben, kann aber genau umgekehrt auch - drastisch formuliert einer Gehirnwäsche gleichkommen.

Die Strukturveränderungen des Kontextes, in dem berufliche Identität behauptet werden muss, können also drei Arten von Identitätsdynamiken auslösen: erstens eine durch Identitätschancen ermöglichte Identitätsbestätigung, zweitens eine Identitätsbehauptung gegen Identitätsbedrohungen sowie drittens eine durch Identitätsbedrohungen auferlegte Identitätsanpassung (siehe Abb. 1.1). Alle drei Richtungen könnten in der deutschen Professorenschaft vorkommen.

Warum es wichtig ist, sich die Frage zu stellen, unter welchen Bedingungen welche der Richtungen wahrscheinlich ist, kann man sich klar machen, wenn man sich abschließend vor Augen führt, wie sich welche Ausrichtung der Identitätsbehauptung auf Forschung und Lehre auswirken könnte.

Ohne hierzu wohlgeordnete Wirkungs-Typologien anbieten zu können, listen wir - das reicht zur Veranschaulichung der Wirkungsbreite aus - bei der Forschung die folgenden Aspekte auf: ${ }^{26}$

- die Anzahl der Publikationen;

- die Qualität der Publikationen gemäß innerwissenschaftlichen Standards;

- die Publikationsformate und -orte;

- die Auswahl der Forschungsthemen;

- die Chance für unorthodoxe, nicht dem fachlichen Mainstream folgende Herangehensweisen;

- das Gewicht außerwissenschaftlicher Relevanzkriterien sowie

- der Nexus von Forschung und Lehre.

\footnotetext{
${ }^{26}$ Zur Einschätzung der Effekte von NPM auf diese Aspekte siehe Barbara Kehm und Ulrike Lanzendorf (2006) sowie Jürgen Enders et al. (2015).
} 


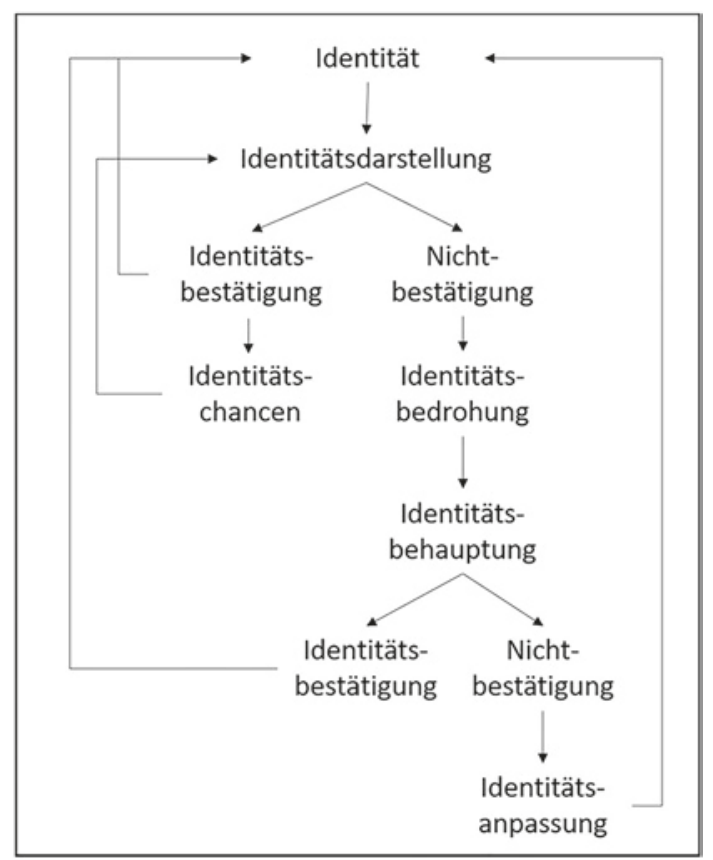

Abb. 1.1 Identitätsdynamiken

Bezüglich der Lehre sind die Hinweise noch fragmentarischer, weil es kaum systematische und mehr als Einzelaspekte erfassende Forschungen zu den Reformeffekten gibt. ${ }^{27}$ Man kann davon ausgehen, dass mindestens die folgenden drei Dimensionen hinsichtlich möglicher Veränderungen in den Blick genommen

\footnotetext{
${ }^{27}$ Hinzu kommt, dass Forschungsergebnisse sehr schnell durch Voreinstellungen der Befürwortung oder Ablehnung der Reformen geprägt werden. Vorliegende Untersuchungen richten ihren Fokus zudem allzu häufig auf allgemeine Zufriedenheitseinschätzungen und Arbeitsbelastungen sowie deren Auswirkungen auf die Lehrmotivation (Schomburg et al. 2012; Bloch et al. 2014). Teilweise wird letztere auch explizit in Zusammenhang mit solchen neuen Instrumenten in Verbindung gebracht, die die Qualitätssteigerung in der Lehre unterstützen sollen (Tremp 2010; Wilkesmann und Schmid 2012, 2014). Evidenzen zu den Auswirkungen auf die qualitativen Aspekte der Lehre - welches Qualitätsverständnis auch immer zugrunde gelegt wird - sind indes rar.
} 
werden sollten: die Planung, die Durchführung und die Ergebnisse der Lehre. So müsste man schauen, ob die Versprechungen von „Bologna“ wie Studierendenzentrierung und Kompetenzorientierung bei der Durchführung sowie die Vermittlung von Schlüsselqualifikationen und die verbesserte „Employability“ bei den Ergebnissen tatsächlich realisiert worden sind und ob andere „Bologna“Elemente nicht vielleicht unerwünschte Nebenwirkungen hervorgerufen haben - etwa die kontinuierlichen studienbegleitenden Prüfungen, die zu einem permanenten statt erst am Studienende auftretenden Prüfungsstress geführt haben könnten, der dem Lernen eher abträglich ist. Weiterhin wäre zu prüfen, ob die intensivierte Konkurrenz um Drittmittel für die Forschung und ein faktisches Übergewicht von Forschungsleistungen im Kriterienkatalog für die Zulagen der W-Besoldung zu einer Vernachlässigung der Lehre durch die ProfessorInnen geführt hat, worauf Studien des gewandelten Zeitbudgets von WissenschaftlerInnen zumindest Hinweise geben (Teichler 2014, S. 69-73; Petersen 2020, S. 195/196). Auch der Nexus von Forschung und Lehre könnte sich verändert haben.

Die aufgelisteten Aspekte reichen zumindest aus, um klar zu machen, dass das, was wir bezüglich der beruflichen Identität von ProfessorInnen ermitteln wollen, sehr folgenreich dafür ist, was die Prinzipale der an den Universitäten erbrachten Forschungs- und Lehrleistungen zukünftig an Leistungen erhalten werden. Dies ist auch deshalb von Interesse, weil die Ursachen der Effekte zu selten identitätstheoretisch in den Blick genommen werden. Werden aber identitätsbezogene Ansprüche verletzt, nützt es wenig, durch Anreize nicht erwünschte Folgen aus dem Weg räumen zu wollen und Reformbereitschaft zu verlangen - sprich wie in einem Interessenkonflikt Kuhhandel zu betreiben.

Damit ist die Darlegung der theoretischen Perspektive, die wir unserer empirischen Untersuchung zugrunde legen, abgeschlossen.

\subsection{Empirisches Vorgehen}

Empirisch beruht unser Vorgehen vor allem auf Leitfadeninterviews mit ProfessorInnen aus verschiedenen Wissenschaftsgebieten. Vorgelagert haben wir eine inhaltsanalytische Auswertung der Medienberichterstattung über die Reformen des deutschen Hochschulsystems. 


\section{Mediendiskurs}

Die zunächst durchgeführte Inhaltsanalyse dient dazu, den Mediendiskurs über die Reformen nachzuvollziehen und dabei vor allem das Bild zu erfassen, das auf der einen Seite die JournalistInnen von den ProfessorInnen zeichnen, das auf der anderen Seite die ProfessorInnen selbst in eigenen Beiträgen abgeben. Die naheliegende Vermutung, dass sich Selbst- und Fremdeinschätzung der Professorenschaft hinsichtlich dessen, was die Reformen bewirkt haben, stark unterscheiden, wird sich - so viel vorab - bestätigen.

$\mathrm{Da}$ es uns nicht um eine umfassende Rekonstruktion dieses Mediendiskurses geht, ${ }^{28}$ sondern lediglich darum, einige typische Schlaglichter zu Anfang der Reformen und etwa zehn Jahre später in den Blick zu nehmen, beschränken wir uns auf ausgewählte Printmedien: die beiden überregionalen Wochenzeitungen DER SPIEGEL und DIE ZEIT sowie die bereits angesprochene F\&L, die monatlich erscheinende Zeitschrift des Deutschen Hochschulverbands. DER SPIEGEL und DIE ZEIT sind Leitmedien, die stärker als andere Wochen- oder Tageszeitungen auf bildungs- und wissenschaftspolitische Themen eingehen; eine erste Sichtung ergab zudem den Eindruck, dass sie - anders als etwa die in der Berichterstattung über Bildung und Wissenschaft eher bildungsbürgerlich ausgerichtete Frankfurter Allgemeine Zeitung oder das dem eher linken Spektrum zuzuordnende Printmedium tageszeitung - überwiegend reformbefürwortend berichten und bewerten. Damit stehen diese beiden Wochenzeitungen und die stark reformkritischen persönlichen Erfahrungsberichte und Meinungsäußerungen von ProfessorInnen, die sich in F\&L finden, an den jeweils entgegengesetzten Enden des Spektrums. In der Zusammenschau ist somit zu erwarten, dass die konträren Sichtweisen auf die Reformen gut zum Ausdruck kommen.

Am ausführlichsten und häufigsten wird in den Medien auf „Bologna“ eingegangen, weil Fragen des Studiums angesichts der weiter wachsenden Studierendenzahlen die größte öffentliche Aufmerksamkeit finden. Die „Exzellenzinitiative“ findet vor allem dann Beachtung, wenn die Förderentscheidungen anstehen, also alle sechs Jahre: Welche Universitäten sind die Gewinner, welche die Verlierer? Immer wieder wird, teilweise im Zusammenhang der anderen beiden Reformen, auch auf Aspekte des NPM eingegangen, wobei diese Reform weniger als die anderen beiden in ihrem Gesamtzuschnitt betrachtet wird, sondern zumeist anlassbezogen einzelne Maßnahmen wie etwa

\footnotetext{
${ }^{28}$ Siehe hierzu aber das interdisziplinäre Handbuch zur Diskursforschung von Johannes Angermüller et al. (2014), das sich mit seinem Untersuchungsobjekt am Beispiel des Diskurses über die Hochschulreformen methodisch und praktisch ausführlich auseinandersetzt.
} 
die Hochschulräte, die Stärkung der Hochschulleitungen oder die W-Besoldung angesprochen werden.

Die von uns ausgewerteten Jahrgänge der genannten Printmedien sind zum einen die Jahre 2000 und 2001, zum anderen die Jahre 2012 und 2013. Um die Jahrtausendwende waren die allerersten Elemente von NPM umgesetzt; „Bologna“ war auf europäischer Ebene gerade beschlossen worden, und die ersten Bundesländer begannen mit der Umsetzung; und es gab die ersten Diskussionen dessen, woraus dann wenig später die „Exzellenzinitiative“ wurde. Zehn Jahre darauf waren alle drei Reformvorhaben umgesetzt und zeigten spürbare Wirkungen. Der Vergleich dieser beiden Zeiträume erlaubt also, den frühen Hoffnungen und Befürchtungen die späteren Erfahrungen und Bewertungen dessen, was tatsächlich eingetreten ist, gegenüberzustellen.

Wir nehmen keine vollständige Auswertung sämtlicher thematisch relevanter Beiträge in den genannten Medien vor. Entsprechend geht es uns auch nicht darum, quantitative Häufigkeiten bestimmter Themen und bestimmter Einschätzungen von Themen zu vergleichen, also etwa aufzuzeigen, dass in F\&L vermutlich viel häufiger und sehr viel kritischer über Zielvereinbarungen zwischen Fachbereichen und Universitätsleitungen berichtet wird als in den beiden Wochenzeitungen, wo aber viel ausführlicher und affirmativer das CHEFächerranking zur Sprache kommt. Für unsere Zwecke reicht es aus, typische Topoi des Diskurses als Kombinationen von in den Blick genommenen Sachverhalten und deren Bewertungen herauszustellen und sich so befürwortende und ablehnende Sichtweisen auf NPM, „Bologna“ und „Exzellenzinitiative“ im Überblick zu vergegenwärtigen.

Was für F\&L aufgrund der Anzahl von zwölf Ausgaben pro Jahr möglich war, konnte für DER SPIEGEL und DIE ZEIT angesichts des wöchentlichen Erscheinungsmodus dieser beiden Printmedien nicht geleistet werden. Anstelle einer vollständigen Sichtung aller Ausgaben erfolgte hier die Suche und Auswahl einschlägiger Artikel anhand von Stichworten in den jeweiligen Online-Archiven. ${ }^{29}$ Ausgeschlossen wurden solche Artikel, die reinen Informationscharakter besaßen, der Fokus richtete sich auf Meinungsartikel. Zudem wurden in F\&L nur die von ProfessorInnen verfassten Beiträge berücksichtigt. Diese wurden als erstes analysiert, um die zentralen Argumente aus ProfessorInnenperspektive in den Blick zu bekommen sowie erste Hinweise auf

\footnotetext{
${ }^{29}$ Auf eine vollständige Auflistung der Suchbegriffe verzichten wir an dieser Stelle. Als Beispiele seien genannt: Hochschulreform, ProfessorInnen, W-Besoldung, Bologna, Universitäten, Hochschulautonomie, Exzellenzinitiative, Studium, Forschung.
} 
Identitätsbedrohungen durch bestimmte reforminduzierte Veränderungen $\mathrm{zu}$ erhalten.

Die Auswertung der ausgewählten Beiträge erfolgte qualitativ-inhaltsanalytisch (Mayring 2015), wobei ein anhand von professions- und wissenschaftssoziologischer Forschung erarbeitetes Codierschema genutzt wurde. Der Fokus wurde auf die Deutungen der Zusammenhänge zwischen den drei Reformvorhaben und den uns interessierenden Aspekten der professoralen Identität (Forschungs- und Lehrethos sowie persönliche Arbeitsautonomie) gelegt.

\section{ProfessorInneninterviews}

Das Hauptinstrument der empirischen Erhebung stellten dann die Leitfadeninterviews dar. Sie sind die Grundlage für die Beantwortung unserer Leitfragen nach den Auswirkungen der durch die Reformen ausgelösten Strukturveränderungen auf die berufliche Identität von ProfessorInnen und deren Identitätsbehauptung insbesondere in ihrem Lehr- und Forschungshandeln. Es war von vornherein klar, dass diese komplexen und noch wenig erforschten Zusammenhänge sich nicht mit einer standardisierten Befragung ermitteln lassen. Auf diese Weise wären höchstens relativ oberflächliche und punktuelle Einzelaspekte der Thematik in den Blick gekommen. Leitfadeninterviews, die im Rahmen einer ganzheitlichen Betrachtung der Arbeitssituation einer Professorin die einzelnen Reformmaßnahmen mit besonderem Akzent auf Leistungsbewertungen ansprechen und dabei so offen angelegt sind, dass die Befragten eigene Akzente setzen, Verbindungen herstellen und auch zusätzliche Aspekte einbringen können, sind hingegen ein gut geeignetes Erhebungsinstrument für die Erkundung der uns interessierenden Zusammenhänge. Freilich sind mit einer solchen qualitativen Herangehensweise keine Häufigkeitsverteilungen feststellbar; dafür wäre eine repräsentative standardisierte Befragung erforderlich. ${ }^{30}$ Das Ergebnis unserer Datenauswertung sind vielmehr Typen und Typologien, also Muster von Wirkungszusammenhängen zwischen strukturellen Kontexten, Identitätserfahrungen und Handlungspraktiken. Nachfolgeuntersuchungen könnten versuchen, diese Muster dann mit standardisierten Items abzubilden und

\footnotetext{
${ }^{30}$ Freilich ließen sich darüber hinaus weitere Argumente für die eine oder die andere methodische Ausrichtung sowie die gewählte Methode - z. B. in Abgrenzung zu anderen qualitativen Verfahren, etwa der Ethnografie - anführen. Deren Vor- und Nachteile - und die darüber durchaus kontrovers geführte Diskussion - sind aber an anderer Stelle gut dokumentiert (Przyborski und Wohlrab-Sahr 2014), weshalb wir an dieser Stelle darauf verzichten möchten.
} 
deren relative Häufigkeiten mit repräsentativen Samples zu bestimmen. Für uns steht demgegenüber das verstehende Erklären der Situationen und Situationsbewältigungen unserer Befragten im Vordergrund. Wir haben die Leitfadeninterviews somit als Experteninterviews eingesetzt, die ProfessorInnen also als in eigener Sache kundige Auskunftsgeber adressiert (Meuser und Nagel 1991; Gläser und Laudel 2010). Im Zentrum stehen, wie auch bei der Medienanalyse, die beiden Themenkomplexe Lehre und Forschung sowie, oft damit verbunden, die persönliche Arbeitsautonomie.

Die Interviews gliederten sich in zwei Erhebungsphasen. In einer ersten explorativen Phase wurden 15 Interviews mit je drei Befragten aus fünf ausgewählten Wissenschaftsgebieten - dazu gleich noch mehr - geführt (siehe Anhang 1). Bei der Auswertung dieser Interviews wurde zunächst stärker induktiv, zum Teil auch fallrekonstruktiv ${ }^{31}$ vorgegangen, um ein möglichst genaues Bild des Spektrums unterschiedlicher Deutungen und der nicht selten komplexen Ambivalenzen in der Bewertung und Bewältigung von Leistungsbewertungen zu bekommen. Wichtig in dieser Phase war die Identifizierung zentraler Ansprüche der ProfessorInnen an Forschung und Lehre. Daraus ergaben sich zum einen wichtige Hinweise für die Konstruktion des Leitfadens für die anschließende Hauptphase der Interviews; man wurde zudem für das Interviewsetting mit seinen Besonderheiten sensibilisiert. Zum anderen stellte sich heraus, dass diese Interviews auch schon für sich genommen so ertragreich waren, dass sie anders als zunächst vorgesehen systematisch und nicht bloß punktuell in die Gesamtauswertung einbezogen werden konnten.

In der Hauptinterviewphase, die von Mai 2015 bis März 2016 dauerte, wurden insgesamt 49 ProfessorInnen aus den ausgewählten Wissenschaftsgebieten und ergänzend 14 Studiendekane und Forschungsreferentinnen befragt. Letztere Interviews dienten der Abrundung des Wissens über die lokalen Bedingungen an denjenigen Universitäten, an denen mehrere ProfessorInnen befragt wurden. Der für die ProfessorInneninterviews benutzte Leitfaden (siehe Anhang 2) ist so aufgebaut, dass in einem einleitenden Teil zunächst die jeweils subjektive Einschätzung der verschiedenen Reformaspekte im eigenen beruflichen Alltag thematisiert wurde. Dieser Einstieg ermöglichte den InterviewpartnerInnen, sich zu den thematisierten Reformveränderungen zu positionieren und ihre eigenen Schwerpunkte zu setzen. Die daran anschließenden Abschnitte widmeten sich jeweils den konkreten Erfahrungen in der Lehre, der Forschung, der Beziehung

\footnotetext{
${ }^{31}$ Zur Methode der Fallrekonstruktion siehe insbesondere Ulrich Oevermann (1981, 2000) sowie Frank Kleemann et al. (2013, S. 111-152).
} 
der beiden Aufgaben zueinander und der Möglichkeit ihrer Integration. Ein gesonderter Teil wandte sich den Leistungsbewertungen und Rechenschaftspflichten zu: der persönlichen Betroffenheit durch diese, dem Umgang mit ihnen und der persönlichen Einschätzung hinsichtlich der Eignung der praktizierten Bewertungsverfahren zur Ermittlung, guter' Lehre und Forschung. Personenbezogene Daten und Informationen zum beruflichen Werdegang, zu aktuellen Forschungsthemen und Lehrangeboten konnten zumeist im Vorfeld im Internet recherchiert werden. Das ersparte zum einen Interviewzeit; zum anderen verbesserte es die Gesprächsatmosphäre: Bei den Befragten kam gut an, dass man sich über sie kundig gemacht hatte und einige Fragen personenspezifisch zuspitzen konnte.

Im Durchschnitt dauerten die Interviews $90 \mathrm{~min}$, wobei die Spanne erheblich war. Das kürzeste währte $40 \mathrm{~min}$, das längste $280 \mathrm{~min}$. Im Vorfeld gab es Hinweise aus anderen vorausgegangenen oder zeitgleichen ProfessorInnenbefragungen, dass es immer schwieriger werde, ProfessorInnen für solche Interviews über die Hochschulreformen und die Folgen für die eigene Arbeitssituation zu gewinnen. Wider Erwarten erwies es sich dann aber schon bei der Interviewanbahnung, dass es kaum Verweigerer gab. Die Interviewatmosphäre und das im Interview Gesagte zeigten insgesamt, dass eine große Bereitschaft bestand, über die von uns aufgeworfenen Fragen nachzudenken und Auskunft zu geben. Ganz offensichtlich nutzten viele Befragte den Gesprächsanlass, um sich selbst besser darüber im Klaren $\mathrm{zu}$ werden, wie die eigene berufliche Situation aussieht und zu bewerten ist - eine für die empirische Sozialforschung sehr günstige Motivation.

Sämtliche 64 Interviews der ProfessorInnenbefragung wurden transkribiert und anschließend computergestützt mit der Auswertungssoftware Atlas.ti kodiert und ausgewertet. Das ex ante aus dem theoretischen und aus erstem empirischen Vorwissen abgeleitete Kategorienschema blieb offen für Ergänzungen, sodass es sich hierbei um ein Wechselspiel aus induktiven, aus den Daten gewonnenen, und deduktiven, theoretisch abgeleiteten Elementen handelt. Das Material haben wir entlang des induktiv-deduktiv konstruierten Kategoriensystems kodiert und sodann in einem zweiten Schritt einer Prüfung unterzogen, die auf die Aufdeckung bestimmter Muster von Merkmalsausprägungen abzielte. Die Auswertung aller Interviews mündete in eine auf vier zentralen Unterscheidungsdimensionen basierenden Typologie. ${ }^{32}$

\footnotetext{
${ }^{32}$ Zur Methodik der empirisch begründeten Typologie siehe Susann Kluge (1999) sowie Udo Kelle und Susann Kluge (2010).
} 


\section{Fallauswahl}

Wie bereits erwähnt, wurden ProfessorInnen aus fünf verschiedenen Wissenschaftsgebieten befragt. Damit wollten wir dem offenkundigen Tatbestand Rechnung tragen, dass Wissenschaft kein homogenes kognitives und soziales Gebilde ist, sondern es - bei allen Gemeinsamkeiten von Wissenschaft als Wertsphäre der modernen Gesellschaft im Unterschied etwa zu Kunst, Religion oder Journalismus (Schimank 2012b) - eine erhebliche Diversität gibt. Bekannt ist die Rede von den „two cultures“ (Snow 1959) der Naturwissenschaften einerseits, der Geisteswissenschaften andererseits. Längst sind daraus unter Verweis auf die Sozialwissenschaften drei Kulturen geworden (Lepenies 1985); und man kann sehr wohl fragen, ob die Ingenieurwissenschaften oder die medizinischen Wissenschaften nicht ebenfalls in vielen Hinsichten ganz eigene Arten wissenschaftlicher Forschung darstellen. ${ }^{33}$ Wir sprechen im Weiteren auch nicht von Disziplinen, weil selbst das noch in vielen Hinsichten wenig homogene Einheiten sind, sondern von subdisziplinären Wissenschaftsgebieten, die auch interdisziplinäre Verknüpfungen von Subdisziplinen mehrerer Disziplinen wie etwa Biochemie sein können.

Es gibt zunächst epistemische Unterschiede zwischen Wissenschaftsgebieten, etwa die Art des Zugriffs auf Empirie oder das Ausmaß der Kodifizierung des erarbeiteten Wissens (Gläser et al. 2010). ${ }^{34}$ Teilweise hängen damit soziale Unterschiede wie z. B. die Konkurrenzintensität in einem Gebiet, die Diversität von Forschungsagenden oder die Publikationsformate zusammen; teilweise ergeben sich diese Unterschiede auch noch aus weiteren Faktoren. Die Wissensproduktion kann dabei in Einzelarbeit erfolgen oder auf Kooperation angewiesen sein, also unterschiedlich stark zergliedert und ressourcenintensiv sein. Die bisher genannten Unterschiede haben weiterhin Auswirkungen auf die Art der Lehre in Wissenschaftsgebieten (Becher 1994; Neumann et al. 2002; Wollin-Giering und Gläser 2016). Wissenschaftsgebiete können ferner, neben innerwissenschaftlichen Relevanzen, in ihrem gesellschaftlichen Bezug mehr oder weniger anwendungs-

\footnotetext{
${ }^{33}$ Hierzu siehe auch die noch weiter differenzierenden Überlegungen von Tony Becher (1994) sowie Becher und Paul R. Trowler (2001), die in Anlehnung an Anthony Biglan (1973) zwischen „hard“ und ,soft disciplines“ unterscheiden und diese nochmals in ,pure“ und ,applied fields" unterteilen, womit auch stärker anwendungsorientierten Fachgebieten wie etwa pädagogischen Teildisziplinen oder den Ingenieurwissenschaften Rechnung getragen wird.

${ }^{34}$ Siehe dazu auch die facettenreiche Fallstudie von Karin Knorr-Cetina (1999) zum Vergleich zweier sehr unterschiedlicher naturwissenschaftlicher „epistemic cultures“.
} 
bezogen sein, und Anwendungsbezug kann Verschiedenes heißen - etwa die Bereitstellung von Technologien oder von Orientierungswissen. Schließlich unterscheidet sich auch der gesellschaftliche Bezug, in dem die Lehre steht wenn es etwa um die Ausbildung von Professionen für relativ spezielle Arbeitsfelder oder um eher generalistische Kompetenzen geht. Für die Lehre macht es auch noch einen Unterschied, ob es sich - aus welchen kontingenten Gründen auch immer - um ein ,Massenfach' oder um ein eher exklusives Fach handelt, in dem auf jeden Lehrenden nur vergleichsweise wenige Studierende kommen.

Bei diesen noch wenig geordneten Andeutungen von relativ augenfälligen Unterschieden müssen wir es, auch angesichts des lückenhaften Forschungsstands, hier belassen. Eine in sich abgestimmte Systematik relevanter Unterschiede zwischen Wissenschaftsgebieten, die eine entsprechend zielgenaue Auswahl von Untersuchungsfällen anleiten könnte, liegt nicht einmal für die epistemischen Unterschiede, geschweige denn unter Einbeziehung der weiteren Dimensionen vor. Um in jedem ausgewählten Wissenschaftsgebiet eine hinreichende Anzahl an ProfessorInnen befragen zu können, konnten wir mit Blick auf unsere Kapazitäten und zeitlichen Möglichkeiten maximal fünf Gebiete betrachten. Vor diesem Hintergrund stellen die folgenden fünf Wissenschaftsgebiete, die wir untersucht haben, keine zwingende Auswahl dar, decken aber doch eine Reihe von vermutlich bedeutsamen Unterschieden ab: ${ }^{35}$

- Zellbiologie: Dies ist ein naturwissenschaftliches Gebiet mit einem - im Vergleich zu den Sozial- und Geisteswissenschaften - hochgradig kodifizierten Stand der Forschung, starker Internationalisierung und Zeitschriftenartikeln als dominantem Publikationsformat. Eine Grundlagenorientierung bei Offenheit für vielfältige, etwa medizinische, Anwendungsbezüge liegt vor. Die Lehre ist gegliedert in die standardisierte Vermittlung von Grundlagenwissen

\footnotetext{
${ }^{35}$ Wir haben bei dieser Auswahl stark von Überlegungen und empirischen Befunden profitiert, die im Projekt „POLGU - Professionelle und organisationale Leistungskriterien für Forschung und Lehre in der Governance der Universitäten“ (Leitung: Jochen Gläser) zeitgleich im gleichen Förderprogramm des BMBF erarbeitet wurden. In zwei der nun anzusprechenden Teildisziplinen, der Zellbiologie und der Vergleichenden Regierungslehre, wurden ergänzend Interviews mit ProfessorInnen aus der Mikrobiologie und den Internationalen Beziehungen geführt. Dies erfolgte nach Rücksprache mit jeweils fachkundigen Experten hinsichtlich der Ähnlichkeiten und Vergleichbarkeit dieser Teildisziplinen. Die Ausweitung diente der Herstellung einer möglichst ausgewogenen Verteilung zwischen den Standorten, Karrierestufen und Geschlechtern.
} 
in den ersten Studienphasen und eine ausgeprägte experimentelle Ausrichtung in späteren Phasen.

- Nachrichten- und Hochfrequenztechnik: Diese ingenieurwissenschaftlichen Teilgebiete mit einem ebenfalls hochgradig kodifizierten Stand der Forschung weisen starke und fokussierte Anwendungsbezüge auf, die vor allem wirtschaftlich interessant sind. Entsprechend geht das Gros der AbsolventInnen in Unternehmen, und die Lehre ist überwiegend auf diese Berufsfelder ausgerichtet. Wissenschaftliche Reputation durch Publikationen und außerwissenschaftliche Arten der Anerkennung durch Unternehmenskontakte oder Patente können im Einzelfall unterschiedlich gewichtet werden.

- Vergleichende Regierungslehre: Dieses sozialwissenschaftliche Gebiet ist eines der seit langem etablierten Standardfelder der Politikwissenschaft. Wie fast alle sozialwissenschaftlichen Gebiete ist es nicht sehr stark kodifiziert, kumulativer Erkenntnisfortschritt wird immer wieder durch paradigmatische Brüche interpunktiert. Die Lehre ist entsprechend pluraler und weniger standardisiert als in den Natur- und Ingenieurwissenschaften. Grundlagenforschung herrscht als Orientierung vor, aber hinzu kommen als Anwendungsbezüge Politikberatung und die Einmischung in öffentliche Debatten. Die Publikationsformate sind vielfältig.

- Strafrecht: Dieses Teilgebiet der Rechtswissenschaft hat die Besonderheit, dass es sich - ähnlich wie bei der Philosophie - nicht um eine empirische Wissenschaft handelt. Rechtswissenschaft ist eine normative Sozialwissenschaft in dem Sinne, dass sie Regeln des sozialen Zusammenlebens in ihrem Sollensgehalt praktisch verbindlich interpretiert. Damit ist der Anwendungsbezug klar, der sich auch in Gesetzeskommentaren und Gutachten als Formaten der Erkenntnispräsentation neben den wissenschaftlichen Publikationsformaten, bei denen Monografien am meisten zählen, manifestiert. Im Großteil der Lehre wird eine hochgradig kodifizierte ,herrschende Meinung' vermittelt, und dies geschieht - da es sich um ein ,Massenfach' handelt - weitgehend in standardisierter Form in großen Vorlesungen.

- Neuere Deutsche Literaturwissenschaft: Dieses Gebiet der Geisteswissenschaften ist in seiner Forschung stark grundlagentheoretisch ausgerichtet, wenn man von feuilletonistischen Beiträgen für literarisch Interessierte absieht. Eine sehr schwache Kodifizierung des Wissensbestands bringt Erkenntnisfortschritt nicht als Kumulation, sondern als Diversifizierung von Lesarten, auch mit starker persönlicher Note, hervor. Die Lehre ist hingegen überwiegend Lehrerausbildung und damit anwendungsbezogene Formung eines literarischen Kanons. Es handelt sich ebenfalls um ein ,Massenfach`. 
Um zumindest anzudeuten, welche weiteren Besonderheiten von Wissenschaftsgebieten mit dieser Auswahl nicht eingefangen werden, sei zum einen auf die sogenannten „Kleinen Fächer“ wie z. B. die Skandinavistik oder die Ägyptologie verwiesen, zum anderen auf ressourcen- und kooperationsintensive „Big Science“ wie etwa in der Teilchenphysik oder der Meeresforschung. Das bedeutet: Alle Ergebnisse unserer Interviews, die wir in den folgenden Kapiteln präsentieren, müssen stets daraufhin , abgeklopft" werden, ob es nicht möglicherweise in den „Kleinen Fächern“, in der „Big Science“ oder in weiteren mit unserer Auswahl von Wissenschaftsgebieten nicht abgedeckten Gebieten in bestimmten Hinsichten anders aussehen könnte.

Neben den Unterschieden zwischen Wissenschaftsgebieten ist ein weiterer augenfälliger Faktor, der Unterschiede in den Erfahrungen und Bewältigungen der Reformmaßnahmen bewirken könnte, die Karrierephase, in der sich jemand befindet, die wiederum erheblich mit dem Alter korreliert. In Deutschland kommt noch hinzu, dass durch die Einführung der W-Besoldung im Jahr 2005 vor allem der - ebenfalls mit dem Alter korrelierende - Zeitpunkt der Berufung darüber bestimmt, ob man noch in die C- oder bereits in die W-Besoldung eingruppiert wurde. Der einfachste Wirkungszusammenhang könnte darin bestehen, dass man ab einer bestimmten fortgeschrittenen Karrierephase kaum noch von Leistungsbewertungen betroffen ist, während umgekehrt diejenigen, die gerade Professor oder Professorin geworden sind, sowohl in ihrer Ressourcenausstattung als auch in ihrem persönlichen Einkommen stark abhängig davon sein können, wie ihre Forschungs- und Lehrleistungen beurteilt werden. Doch es könnte noch weitere, weniger auf der Hand liegende Zusammenhänge geben, die wir nicht übersehen wollen. Daher haben wir bei der Auswahl der Interviewten auch darauf geachtet, dass wir verschiedene Karrierephasen in den Blick bekommen. Genauer haben wir für jedes Wissenschaftsgebiet eine Zusammenstellung von Fällen gesucht und weitgehend auch realisieren können, die ab dem ProfessorInnenstatus unterschiedliche Karriere- und Besoldungsstufen enthält: von jüngeren ProfessorInnen mit Erstberufung, die am Anfang ihrer ProfessorInnenkarriere waren, ${ }^{36}$ bis zu ProfessorInnen, die zum Zeitpunkt der Erhebung kurz vor der Emeritierung standen, möglicherweise schon mehrere universitäre Stationen durchlaufen hatten und bereits ein vergleichendes Resümee ziehen konnten. Wir haben überdies auch

\footnotetext{
${ }^{36}$ Wobei uns hier daran gelegen war, dass unsere InterviewpartnerInnen bereits über hinreichende Erfahrungen mit den universitären Wandlungsprozessen und Leistungsbewertungsverfahren verfügten, weshalb wir bei der Auswahl darauf geachtet haben, dass seit der Erstberufung mindestens fünf Jahre vergangen waren.
} 
auf eine Verteilung geachtet, die hinreichend viele Professorinnen enthält - was in der Neueren Deutschen Literaturwissenschaft nicht schwierig ist, in der Nachrichtentechnik aber sehr wohl. ${ }^{37}$

Schließlich war uns daran gelegen, eine gewisse Vielfalt der Umsetzung von NPM und „Bologna“ sowie von Erfahrungen mit der „Exzellenzinitiative“ einzufangen. Wir haben die Befragten daher weitgehend an den Universitäten zweier Bundesländer ausgewählt, die sich hinsichtlich ihres hochschulpolitisch artikulierten ,Reformeifers ' deutlich unterscheiden, wo also die Strukturveränderungen und ihre Auswirkungen auf die professorale Identität unterschiedlich stark ausgefallen sein könnten. ${ }^{38}$ Zudem haben wir in jedem der Länder sowohl Fälle an Traditionsuniversitäten als auch an Neugründungen aus den 1960er und 1970er Jahren untersucht, weil die Grundausstattung der zumeist auch kleineren Neugründungen oft schlechter als die der Traditionsuniversitäten ist.

Dies waren die Auswahlkriterien für unsere Befragten. In der Zusammenschau bilden sie nach unserer Einschätzung einen erheblichen Teil der empirisch vorfindlichen Varianz mit Blick auf unsere Fragestellung ab, wenngleich bestimmte Partien des Gesamtbildes angesichts des begrenzten Umfangs unserer Studie fehlen müssen.

\subsection{Vorschau}

Damit haben wir den interessierenden Untersuchungsgegenstand sowie die Anlage der Untersuchung in theoretischer und empirischer Hinsicht dargelegt. Wir geben nun noch eine Vorschau auf den Gang der Ergebnisdarstellung in den folgenden Kapiteln.

Das Kap. 2 beschäftigt sich mit dem Mediendiskurs über die Reformen mit besonderem Augenmerk auf journalistische ReformbefürworterInnen einer-

\footnotetext{
${ }^{37}$ Um es genauer zu sagen: Während sich in der Neueren Deutschen Literaturwissenschaft eine weitgehende Gleichverteilung realisieren ließ, ist in unserem Sample der Nachrichtenund Hochfrequenztechnik keine einzige Frau vertreten. Insgesamt wurden mehr Männer als Frauen interviewt, mit einem Frauenanteil von fast genau einem Viertel entspricht dies in etwa auch der tatsächlichen damaligen Verteilung in Deutschland (eigene Berechnung, basierend auf Daten des Statistischen Bundesamtes: Statistisches Bundesamt 2017).

${ }^{38}$ Ein Indikator dafür ist das Ausmaß der rechtlichen Neuregelungen, die Otto Hüther (2010) auch ländervergleichend betrachtet hat. Ute Lanzendorf und Peer Pasternack (2016) kamen in einer aktuelleren Sichtung der Hochschulreformen im Ländervergleich zuletzt zu dem Ergebnis, dass hier - durch Ent- oder Verschärfung eingeleiteter Maßnahmen - eine gewisse Konvergenz zu verzeichnen ist.
} 
seits, professorale ReformgegnerInnen andererseits. Damit wird der von Anfang an die Thematik beherrschende Deutungskampf akzentuiert. Während die ReformbefürworterInnen sich von den Reformen deutliche Verbesserungen der Qualität von Forschung und Lehre versprechen und einen erforderlichen Wandel der beruflichen Identität der ProfessorInnen als Folge bzw. Voraussetzung der Reformen ansprechen, wollen die ReformgegnerInnen unter den ProfessorInnen die in ihren Augen bewährte berufliche Identität und damit das bisherige Forschungs- und Lehrethos sowie ihre Arbeitsautonomie wahren.

Im Kap. 3 beginnt die Interviewauswertung. Es geht zunächst darum, Vorstellungen der ProfessorInnen darüber herauszuarbeiten, was ,gute' Lehre und Forschung jeweils ausmacht. Denn diese Vorstellungen sind als Identitätskomponenten der Maßstab, anhand dessen die von den Reformvorhaben hervorgebrachten Strukturveränderungen, insbesondere die mit Leistungsbewertungen verbundenen, beurteilt werden. Bereits hier werden, bei vielen Gemeinsamkeiten der meisten Befragten, Unterschiede zwischen den Wissenschaftsgebieten sowie zwischen den Karrierestufen erkennbar.

Das Kap. 4 wendet sich dann der Verarbeitung der Strukturveränderungen zu: Wie werden sie, insbesondere als Leistungsbewertungen, von den ProfessorInnen mit Blick auf die je eigene Identität erfahren - als Identitätsbedrohungen oder Identitätschancen? Und wie gehen die ProfessorInnen dann mit beidem in ihren Forschungs- und Lehrpraktiken um? In diesem Kapitel stehen drei individuelle Fälle im Vordergrund. Diese dienen als ganzheitliche Rekonstruktionen dazu, die Komplexität und die vielfältigen Ambivalenzen der Identitätsbetroffenheit und -behauptung der ProfessorInnen im konkreten Einzelfall zu veranschaulichen. Hier kommt, neben den Wissenschaftsgebieten und den Karrierestufen, auch die organisationale Umsetzung der Reformen als weitere wichtige Determinante der Wirkungszusammenhänge ins Spiel. Bereits diese Fälle zeigen, dass das im Mediendiskurs vorherrschende Stereotyp des reformverweigernden Professors egal, ob als Schurke oder als Held gesehen - viel zu simpel gestrickt ist. ${ }^{39}$

Im Kap. 5 wird dann anhand aller untersuchten Fälle eine differenzierte Typologie der Verarbeitung der Reformen durch die ProfessorInnen ausgearbeitet. Im Einzelnen werden unterschieden: der Gelassene - die Verschonte - der Sympathisant - das Reformopfer - der Wehrhafte - die Zuversicht-

\footnotetext{
${ }^{39}$ Dass die Gegenfigur, der ,,akademische Kapitalist“, wie er von einigen reformkritischen Autoren, so etwa von Richard Münch (2011), gezeichnet wird, ebenfalls unterkomplex ist, soll an dieser Stelle nicht unerwähnt bleiben.
} 
liche - der Profiteur. ${ }^{40}$ Jeder der Typen ist eine in sich stimmige Art der Identitätsbehauptung, die bei einem jeweils nennenswerten Teil der ProfessorInnen - wenngleich nicht gleichverteilt - vorherrschen dürfte. Diese Typenbildung ist zwischen den drei herausgegriffenen ganzheitlichen Fällen auf der einen und dem Stereotyp des Reformverweigerers auf der anderen angesiedelt: weniger ,lebensecht' als die Fälle, aber mit sehr viel mehr ,Fleisch an den Knochen“ als der Pappkamerad des medialen Diskurses. Es zeigt sich, dass nicht nur vielerlei kontingente Faktoren dafür sorgen, dass es ein Spektrum an Reformerfahrungen und -bewältigungen gibt: Welchem dieser Typen jemand zugeordnet ist, hängt vielmehr in erheblichem Maße vom Wissenschaftsgebiet, von der Karrierephase und von der organisationalen Umsetzung der Reformen vor Ort ab. Und warum es wiederum wichtig ist, sich dieser Thematik aus einer identitätstheoretischen Perspektive anzunähern, sollte die - hier schon angedeutete - Wirkungsbreite der Identitätsbehauptung bereits verdeutlicht haben. Darüber hinaus stellen viele der hier beschriebenen Arten der Situationsbewältigung Reaktionen dar, deren Ursachen zum einen - der Komplexität des Reformgeschehens, aber auch den Determinanten der Typenzugehörigkeit und ihren Wechselwirkungen geschuldet - vielschichtiger und damit zum anderen auch schwerer gestaltbar sind.

Das abschließende Kap. 6 wendet sich, ausgehend von einem Resümee der Ergebnisse, alternativen Zukunftsszenarien zu. Wenn die gegenwärtige ,Großwetterlage' in der Professorenschaft durch die genannten Typen gekennzeichnet ist: Wie könnte sich das unter welchen Randbedingungen einschließlich weiterer hochschulpolitischer Interventionen - weiter entwickeln? Und welche Auswirkungen könnten sich auf Forschung und Lehre ergeben? Wir werden diese Fragen, die jedem, der auf die eine oder andere Weise ins Hochschulsystem involviert ist, unter den Nägeln brennen sollten, hier nicht abschließend beantworten können. Aber wir weisen auf das, was mit der beruflichen Identität der ProfessorInnen weiter geschehen könnte, als einen Teil der Antwort hin, den zu ignorieren ignorant wäre.

\footnotetext{
${ }^{40}$ Die männliche und weibliche Typenbezeichnung erfolgt hier alternierend und soll keine Rückschlüsse auf die empirisch vorgefundene Zuordnung geben. Hierzu aber mehr in Kap. 5.
} 


\section{Literatur}

Akerlof, George A. 1970. The market for lemons: Quality uncertainty and the market mechanism. Quarterly Journal of Economics 84: 488-500.

Alexander von Humboldt-Stiftung (Hrsg.). 2009. Publikationsverhalten in unterschiedlichen wissenschaftlichen Disziplinen. Beiträge zur Beurteilung von Forschungsleistungen. Diskussionspapier Nr. 12. Bonn: Alexander von Humboldt-Stiftung.

Aljets, Enno. 2015. Der Aufstieg der Empirischen Bildungsforschung. Ein Beitrag zur institutionalistischen Wissenschaftssoziologie. Wiesbaden: Springer VS.

Anderson, Gina. 2008. Mapping academic resistance in the Managerial university. Organization 15: 251-270.

Angermüller, Johannes, Martin Nonhoff, Eva Herschinger, Felicitas Macgilchrist, Martin Reisigl, Juliette Wedl, Daniel Wrana, und Alexander Ziem (Hrsg.). 2014. Diskursforschung. Ein interdisziplinäres Handbuch, Bd. Bielefeld: transcript.

Aubert, Vilhelm. 1963. Competition and dissensus: Two types of conflict and of conflict resolution. Journal of Conflict Resolution 7 (1): 26-42.

Barry, Jim, John Chandler, und Heather Clark. 2001. Between the ivory tower and the academic assembly line. Journal of Management Studies 38 (1): 88-101.

Becher, Tony. 1994. The significance of disciplinary differences. Studies in Higher Education 19 (2): 151-161.

Becher, Tony, und Paul R. Trowler. 2001. Academic tribes and territories: Intellectual enquiry and the culture of disciplines. Buckingham: Open University Press.

Biglan, Anthony. 1973. The characteristics of subject matter in different academic areas. Journal of Applied Psychology 57 (3): 195-203.

Binner, Kristina, Bettina Kubicek, Anja Rozwandowicz, und Lena Weber, Hrsg. 2013. Die unternehmerische Hochschule aus der Perspektive der Geschlechterforschung. Münster: Westfälisches Dampfboot.

Binner, Kristina, und Lena Weber. 2019. Zwischen ,Exzellenz“ und Existenz. Wissenschaftskarriere, Arbeits- und Geschlechterarrangements in Deutschland und Österreich. GENDER 11 (1): 31-46.

Bloch, Roland, Monique Lathan, Alexander Mitterle, Doreen Trümpler, und Carsten Würmann. 2014. Wer lehrt warum? Strukturen und Akteure der akademischen Lehre an deutschen Hochschulen. Leipzig: AVA - Akademische Verlagsanstalt.

Bogumil, Jörg, and Rolf G. Heinze. 2009. Neue Steuerung von Hochschulen: Eine Zwischenbilanz. Berlin: sigma.

Bogumil, Jörg, Rolf G. Heinze, Stephan Grohs, und Sascha Gerber. 2007. Hochschulräte als neues Steuerungsinstrument? Eine empirische Analyse der Mitglieder und Aufgabenbereiche. Abschlussbericht der Kurzstudie. Dortmund: Hans-Böckler-Stiftung.

Bogumil, Jörg, Martin Burgi, Rolf G. Heinze, Sascha Gerber, Ilse-Dore. Gräf, Linda Jochheim, Maren Schickentanz, und Manfred Wannöffel. 2013. Modernisierung der Universitäten. Umsetzungsstand und Wirkungen neuer Steuerungsinstrumente. Berlin: sigma.

Böhlke, Nils, Thomas Gerlinger, Kai Mosebach, Rolf Schmucker, und Thorsten Schulten, Hrsg. 2009. Privatisierung von Krankenhäusern. Erfahrungen und Perspektiven aus Sicht der Beschäftigten. Hamburg: VSA. 
Bologna-Deklaration. 1999. Der Europäische Hochschulraum. Gemeinsame Erklärung der Europäischen Bildungsminister, 19. Juni 1999, Bologna. https://www.bmbf.de/files/ bologna_deu.pdf.

Bröckling, Ulrich. 2007. Das unternehmerische Selbst. Frankfurt a. M.: Suhrkamp.

Bröckling, Ulrich, und Tobias Peter. 2017. Das Dispositiv der Exzellenz. Zur Gouvernementalität ökonomischer Arrangements an Hochschulen. In Dispositiv und Ökonomie. Diskurs- und dispositivanalytische Perspektiven auf Märkte und Organisationen, Hrsg. Rainer Diaz-Bone und Ronald Hartz, 283-303. Wiesbaden: Springer VS.

Bröckling, Ulrich, Susanne Krasmann, und Thomas Lemke, Hrsg. 2004. Glossar der Gegenwart. Frankfurt a. M.: Suhrkamp.

Burke, Peter J., und Jan E. Stets. 2009. Identity theory. Oxford: Oxford University Press.

Cast, Alicia D., und Jan E. Stets. 2016. The self. In Handbook of contemporary social theory, Hrsg. Seth Abrutyn, 343-365. Cham: Springer International Publishing.

Clegg, Sue. 2008. Academic identities under threat? British Educational Research Journal 34 (3): 329-345.

Courpasson, David, und Steven Vallas, Hrsg. 2016. The SAGE handbook of resistance. Los Angeles: SAGE.

Dammayr, Maria. 2019. Legitime Leistungspolitiken? Leistung, Gerechtigkeit und Kritik in der Altenpflege. Weinheim: Beltz Juventa.

Defazio, Daniela, Andy Lockett, und Mike Wright. 2009. Funding incentives, collaborative dynamics and scientific productivity: Evidence from the EU framework program. Research Policy 38 (2): 293-305.

Detmer, Hubert, und Ulrike Preißler. 2006. Die W-Besoldung und ihre Anwendung in den Bundesländern. Beiträge Zur Hochschulforschung 28 (2): 50-66.

DHV (Deutscher Hochschulverband). 1991. Das Berufsbild des Universitätslehrers. Bonn: Deutscher Hochschulverband.

Dohmen, Dieter, und Lena Wrobel. 2018. Entwicklung der Finanzierung von Hochschulen und Außeruniversitären Forschungseinrichtungen seit 1995. Berlin: Forschungsinstitut für Bildungs- und Sozialökonomik.

Draheim, Susanne. 2012. Das lernende Selbst in der Hochschulreform: »Ich« ist eine Schnittstelle. Subjektdiskurse des Bologna-Prozesses. Bielefeld: transcript.

Ebers, Mark, und Wilfried Gotsch. 1998. Institutionenökonomische Theorien der Organisation. In Organisationstheorien, Hrsg. Alfred Kieser, 199-251. Stuttgart: Kohlhammer.

Ehrmann, Thomas. 2015. Der gefesselte Professor - Über die Folgen von studentischen Lehrevaluationen. Forschung Und Lehre 9: 724-725.

Enders, Jürgen, und Ulrich Teichler. 1995. Der Hochschullehrerberuf im internationalen Vergleich. Ergebnisse einer Befragung über die wissenschaftliche Profession in 13 Ländern. Bonn: Bundesministerium für Bildung, Wissenschaft, Forschung und Technologie.

Enders, Jürgen, Barbara M. Kehm, and Uwe Schimank. 2015. Turning universities into actors on quasi-markets: How new public management reforms affect academic research. In The changing governance of higher education and research - Multilevel perspectives, ed. Dorothea Jansen and Insa Pruisken, 89-103. Dordrecht: Springer.

Espeland, Wendy Nelson, und Michael Sauder. 2016. Engines of anxiety: Academic rankings, reputation, and accountability. New York: Russell Sage Foundation. 
Espeland, Wendy Nelson, und Mitchell L. Stevens. 1998. Commensuration as a social process. Annual Review of Sociology 24 (1): 313-343.

Espeland, Wendy Nelson, und Michael Sauder. 2007. Rankings and reactivity: How public measures recreate social worlds. American Journal of Sociology 113 (1): 1-40.

Etzioni, Amitai. 1969a. Preface. In The semi-professions, Hrsg. Amitai Etzioni, v-xviii. New York: Free Press.

Etzioni, Amitai, Hrsg. 1969b. The semi-professions and their organizations. New York: Free Press.

Europäische Kommission. 2006. Council Decision of 19 December 2006 concerning the Specific Programme "Cooperation" implementing the Seventh Framework Programme of the European Community for research, technological development and demonstration activities (2007-2013). Official Journal of the European Union. https:// eur-lex.europa.eu/LexUriServ/LexUriServ.do?uri=OJ:L:2006:400:0086:0242:en:PDF.

Europäische Kommission. 2007. Das Siebte Rahmenprogramm (RP7). Europäische Forschung auf dem Vormarsch. https://ec.europa.eu/research/fp7/pdf/fp7-brochure_ de.pdf.

Evetts, Julia. 2013. Professionalism: Value and ideology. Current Sociology 61 (5-6): 778796.

Flecker, Jörg, Franz Schultheis, und Berthold Vogel, Hrsg. 2014. Im Dienste öffentlicher Güter. Metamorphosen der Arbeit aus der Sicht der Beschäftigten. Berlin: sigma.

Flink, Tim, und Dagmar Simon. 2014. Erfolg in der Wissenschaft. Von der Ambivalenz klassischer Anerkennung und neuer Leistungsmessung. In Erfolg. Konstellationen und Paradoxien einer gesellschaftlichen Leitorientierung, Hrsg. Denis Hänzi, Hildegard Matthies, und Dagmar Simon, 123-144. Baden-Baden: Nomos.

Friedrich, Hans R. 2006. Ergänzende Anmerkungen zum Beitrag von Uwe Schimank und Stefan Lange ,Hochschulpolitik in der Bund-Länder-Konkurrenz'. In Das Wissensministerium. Ein halbes Jahrhundert Forschungs- und Bildungspolitik in Deutschland, Hrsg. Peter Weingart und Niels C. Taubert, 481-486. Weilerswist: Velbrück.

Funken, Christiane, Jan-Christoph Rogge, und Sinje Hörlin. 2015. Vertrackte Karrieren. Zum Wandel der Arbeitswelten in Wirtschaft und Wissenschaft. Frankfurt: Campus.

Gassmann, Freya. 2018. Wissenschaft als Leidenschaft? Über die Arbeits- und Beschäftigungsbedingungen wissenschaftlicher Mitarbeiter. Frankfurt: Campus.

Gergen, Kenneth J. 1971. The concept of self. New York: Holt, Rinehart and Winston.

Gläser, Jochen. 2006. Wissenschaftliche Produktionsgemeinschaften. Die soziale Ordnung der Forschung. Frankfurt a. M.: Campus.

Gläser, Jochen, und Stefan Lange. 2007. Wissenschaft. In Handbuch Governance, Hrsg. Arthur Benz, Susanne Lütz, Uwe Schimank, und Georg Simonis, 437-451. Wiesbaden: VS.

Gläser, Jochen, Stefan Lange, Grit Laudel, und Uwe Schimank. 2010. The limits of universality: How field-specific epistemic conditions affect authority relations and their consequences. In Reconfiguring knowledge production. Changing authority relationships in the sciences and their consequences for intellectual innovation, Hrsg. Richard Whitley, Jochen Gläser, und Lars Engwall, 291-324. Oxford: Oxford University Press.

Gläser, Jochen, und Grit Laudel. 2010. Experteninterviews und qualitative Inhaltsanalyse. Wiesbaden: VS Verlag. 
Gläser, Jochen, und Uwe Schimank. 2014. Autonomie als Resistenz gegen Beeinflussung - Forschungshandeln im organisatorischen und politischen Kontext. In Autonomie revisited. Beiträge zu einem umstrittenen Grundbegriff in Wissenschaft, Kunst und Politik. Zeitschrift für soziologische Theorie, Sonderbd. 2. Hrsg. Martina Franzen, Arlena Jung, David Kaldewey, und Jasper Korte, 41-61. Weinheim: Beltz Juventa.

Glotz, Peter. 1996. Im Kern verrottet? Fünf vor zwölf an Deutschlands Universitäten. Stuttgart: Deutsche Verlags-Anstalt.

Goffman, Erving. 1963. Stigma. Harmondsworth [1974]: Penguin Books.

Gold, Andreas. 2015. Im Absurdistan der Leistungsberechnung - ECTS-Punkte im Studium ohne Anwesenheit. Forschung Und Lehre 11: 920-922.

Heintz, Bettina. 2008. Governance by numbers. Zum Zusammenhang von Quantifizierung und Globalisierung am Beispiel der Hochschulpolitik. In Governance von und durch Wissen, Hrsg. Gunnar Folke Schuppert und Andreas Voßkuhle, 110-128. Baden Baden: Nomos.

Henkel, Mary. 2000. Academic identities and policy change in higher education. London: Jessica Kingsley.

Henkel, Mary. 2005. Academic identity and autonomy in a changing environment. Higher Education 49: 155-176.

Henkel, Mary, und Agnete Vabo. 2006. Academic identities. In Transforming higher education. A comparative study, Hrsg. Maurice Kogan, Ivar Bleiklie, Marianne Bauer, und Mary Henkel, 127-160. Dordrecht: Springer.

Hillmer, Marita, und Katharina Al-Shamery, Hrsg. 2015. Die Bedeutung von Bildung in einer Dienstleistungs- und Wissensgesellschaft. Welchen Bildungsauftrag hat die Universität? Nova Acta Leopoldina, Neue Folge, Bd. 121. Stuttgart: Wissenschaftliche Verlagsgesellschaft.

Hirschman, Albert O. 1994. Wieviel Gemeinsinn braucht die liberale Gesellschaft? Leviathan 22 (2): 293-304.

HIS Hochschul-Informations-System Hrsg. 2010. Perspektive Studienqualität. Bielefeld: Bertelsmann

Höhle, Ester Ava, und Ulrich Teichler. 2013. The academic profession in the light of comparative surveys. In The academic profession in Europe: New tasks and new challenges, Hrsg. Barbara M. Kehm und Ulrich Teichler, 23-38. Dordrecht: Springer.

Holtgrewe, Ursula, Stefan Voswinkel, und Gabriele Wagner, Hrsg. 2000. Anerkennung und Arbeit. Konstanz: UVK.

Honneth, Axel. 1992. Kampf um Anerkennung. Zur moralischen Grammatik sozialer Konflikte. Frankfurt a. M.: Suhrkamp.

Honneth, Axel. 2010. Das Ich im Wir. Studien zur Anerkennungstheorie. Frankfurt a. M.: Suhrkamp.

Honneth, Axel, Ophelia Lindemann, und Stephan Voswinkel, Hrsg. 2012. Strukturwandel der Anerkennung. Paradoxien sozialer Integration in der Gegenwart. Frankfurt a. M.: Campus.

Hüther, Otto. 2009. Hochschulräte als Steuerungsakteure? Beiträge Zur Hochschulforschung 31 (2): 50-73.

Hüther, Otto. 2010. Von der Kollegialität zur Hierarchie. Eine Untersuchung des New Managerialism in den Landeshochschulgesetzen. Wiesbaden: VS.

Hüther, Otto, und Georg Krücken. 2016. Hochschulen - Fragestellungen, Ergebnisse und Perspektiven der sozialwissenschaftlichen Hochschulforschung. Wiesbaden: Springer VS. 
Jacob, Anna Katharina, und Ulrich Teichler. 2011. Der Wandel des Hochschullehrerberufs im internationalen Vergleich. Ergebnisse einer Befragung in den Jahren 2007/08. Bielefeld: Bertelsmann.

Jaeger, Michael, Michael Leszczensky, Dominic Orr, und Astrid Schwarzenberger. 2005. Formelgebundene Mittelvergabe und Zielvereinbarungen als Instrument der Budgetierung an deutschen Universitäten: Ergebnisse einer bundesweiten Befragung. HIS Kurzinformation A/13/2005. Hannover: HIS.

Jochheim, Linda, Jörg Bogumil, und Rolf G. Heinze. 2016. Hochschulräte als neues Steuerungsinstrument von Universitäten? Eine empirische Analyse ihrer Wirkungsweise. Der Moderne Staat 9: 203-225.

Kamenz, Uwe, und Martin Wehrle. 2007. Professor Untat. Was faul ist hinter den Hochschulkulissen. Berlin: Econ.

Kaufmann, Benedict. 2012. Akkreditierung als Mikropolitik. Zur Wirkung neuer Steuerungsinstrumente an deutschen Hochschulen. Wiesbaden: Springer VS.

Kehm, Barbara, und Ute Lanzendorf. 2006. Germany - 16 Länder approaches to reform. In Reforming university governance - Changing conditions for research in four European countries, Hrsg. Barbara Kehm und Ute Lanzendorf, 135-186. Bonn: Lemmens.

Kelle, Udo, und Susann Kluge. 2010. Vom Einzelfall zum Typus - Fallvergleich und Fallkontrastierung in der qualitativen Sozialforschung. Wiesbaden: VS.

Kieser, Alfred. 2020. 20 Jahre „Entfesselung deutscher Hochschulen“. Eine Kritische Bilanz. Forschung \& Lehre 7: 588-589.

Kivistö, Jussi, und Inga Zalyevska. 2015. Agency theory as a framework for higher education governance. In The Palgrave international handbook of higher education policy and governance, Hrsg. Jeroen Huisman, Harry de Boer, David D. Dill, und Manuel Souto-Otero, 132-151. London: Palgrave Macmillan.

Kleemann, Frank, Uwe Krähnke, und Ingo Matuschek. 2013. Interpretative Sozialforschung. Eine Einführung in die Praxis des Interpretierens. Wiesbaden: VS.

Kleimann, Bernd. 2016b. Universitätsorganisation und präsidiale Leitung. Führungspraktiken in einer multiplen Hybridorganisation. Wiesbaden: Springer VS.

Kloke, Katharina. 2014. Qualitätsentwicklung an deutschen Hochschulen. Professionstheoretische Untersuchung eines neuen Tätigkeitsfeldes. Wiesbaden: VS.

Kluge, Susann. 1999. Empirisch begründete Typenbildung. Zur Konstruktion von Typen und Typologien in der qualitativen Sozialforschung. Wiesbaden: VS.

Knorr-Cetina, Karin. 1999. Epistemic cultures: How the sciences make knowledge. Cambridge: Harvard University Press.

Koch, Juliane. 2010. Leistungsorientierte Professorenbesoldung. Rechtliche Anforderungen und Gestaltungsmöglichkeiten für die Gewährung von Leistungsbezügen der W-Besoldung. Frankfurt a. M.: Lang.

Kräkel, Matthias. 2006. Zur Reform der Professorenbesoldung in Deutschland. Perspektiven der Wirtschaftspolitik 7 (1): 105-126.

Kühn, Hagen. 2004. Die Ökonomisierungstendenz in der medizinischen Versorgung. In Markt versus Solidarität. Gesundheitspolitik im deregulierten Kapitalismus, Hrsg. Gine Elsner, Thomas Gerlinger, und Klaus Stegmüller, 25-41. Hamburg: VSA.

Laing, Ronald D. 1961. Das Selbst und die Anderen. Reinbek [1977]: Rowohlt.

Lamont, Michèle. 2012. Toward a comparative sociology of valuation and evaluation. Annual Review of Sociology 38: 201-221. 
Lange, Stefan. 2008. Hochschulräte. In Handbuch Wissenschaftspolitik, Hrsg. Dagmar Simon, Andreas Knie, und Stefan Hornbostel, 347-362. Wiesbaden: VS.

Lange, Stefan, und Uwe Schimank. 2006. Hochschulpolitik in der Bund-LänderKonkurrenz. In Das Wissensministerium - Ein halbes Jahrhundert Forschungs- und Bildungspolitik in Deutschland, Hrsg. Peter Weingart und Niels C. Taubert, 311-346. Weilerswist: Velbrück.

Lanzendorf, Ute, und Peer Pasternack. 2016. Landeshochschulpolitiken nach der Föderalismusreform. In Die Politik der Bundesländer. Zwischen Föderalismusreform und Schuldenbremse, Hrsg. Achim Hildebrandt und Frieder Wolf, 35-59. Wiesbaden: Springer VS.

Leibfried, Stephan, Hrsg. 2010. Die Exzellenzinitiative. Zwischenbilanz und Perspektiven. Frankfurt a. M.: Campus.

Leibfried, Stephan, und Ulrich Schreiterer. 2015. Die Exzellenzinitiative. Ein Fortsetzungsroman. Wissenschaft im Dialog 13/2015. Berlin: Berlin-Brandenburgische Akademie der Wissenschaften.

Lepenies, Wolf. 1985. Die drei Kulturen. Soziologie zwischen Literatur und Wissenschaft. München: Hanser.

Leszczensky, Michael, and Dominic Orr. 2004. Staatliche Hochschulfinanzierung durch indikatorgestützte Mittelverteilung. Dokumentation und Analyse der Verfahren in 11 Bundesländern. HIS-Kurzinformationen A/2/2004. Hannover: HIS.

Lohr, Karin, Thorsten Peetz, und Romy Hilbrich. 2013a. Bildungsarbeit im Umbruch. Zur Ökonomisierung von Arbeit und Organisation in Schulen, Universitäten und in der Weiterbildung. Berlin: sigma.

Lohr, Karin, Thorsten Peetz, und Romy Hilbrich. 2013b. Verunsicherung und Eigensinn. Bildungsarbeit in Reorganisationsprozessen. Journal Für Psychologie 21 (3): 32.

Luhmann, Niklas. 1997. Die Gesellschaft der Gesellschaft. Frankfurt a. M.: Suhrkamp.

Maasen, Sabine, und Peter Weingart. 2008. Unternehmerische Universität und neue Wissenschaftskultur. In Wissenschaft unter Beobachtung. Effekte und Defekte von Evaluationen, Hrsg. Hildegard Matthies und Dagmar Simon, 141-160. Wiesbaden: VS.

Massih-Tehrani, Nilgun, Christian Baier, and Vincent Gengnagel. 2015. EU-Forschungsförderung im deutschen Hochschulraum. Soziale Welt 66 (1): 55-74.

Matthies, Hildegard. 2016. Akademischer Hazard und berufliche Identitäten. In Wissenschaftliche Karriere als Hazard. Eine Sondierung, ed. Julia Reuter, Oliver Berli, and Manuela Zinnbauer, 29-48. Frankfurt a. M.: Campus.

Mayntz, Renate. 2002. University councils. An institutional innovation in German universities. European Journal of Education 37: 21-28.

Mayring, Philipp. 2015. Qualitative Inhaltsanalyse. Grundlagen und Techniken. Weinheim: Beltz.

Meier, Frank, und Uwe Schimank. 2002. Szenarien der Profilbildung im deutschen Hochschul-System. Einige Vermutungen. Die Hochschule 1: 82-91.

Meier, Frank, und Uwe Schimank. 2010. Mission Now Possible: Profile Building and Leadership in German Universities. In Reconfiguring knowledge production. Changing authority relationships in the sciences and their consequences for intellectual innovation, Hrsg. Richard Whitley, Jochen Gläser, und Lars Engwall, 211-236. Oxford: Oxford University Press. 
Meier, Frank, und Uwe Schimank. 2012. Organisation und Organisationsgesellschaft. Studienbrief: FernUniversität in Hagen.

Meier, Frank, und Uwe Schimank. 2014. Cluster-building and the transformation of the university. Soziologie 43: 139-166.

Meier, Frank, Thorsten Peetz, and Désirée. Waibel. 2016. Bewertungskonstellationen. Theoretische Überlegungen zur Soziologie der Bewertung. Berliner Journal für Soziologie 26: 307-328.

Merton, Robert K. 1942. The Normative Structure of Science. In The Sociology of Science, Hrsg. Robert K. Merton, 267-278. Chicago [1973]: University of Chicago Press.

Meuser, Michael, und Ulrike Nagel. 1991. ExpertInneninterviews - Vielfach erprobt, wenig bedacht: ein Beitrag zur qualitativen Methodendiskussion. In Qualitativ-empirische Sozialforschung: Konzepte, Methoden, Analysen, Hrsg. Detlef Garz und Klaus Kraimer, 441-471. Opladen: Westdeutscher Verlag.

Minssen, Heiner, Beate Molsich, Uwe Willkesmann, und Uwe Andersen. 2003. Kontextsteuerung von Hochschulen? Folgen der indikatorisierten Mittelzuweisung. Berlin: Duncker \& Humblot.

Mintzberg, Henry. 1979. The structuring of organizations: A synthesis of the research. Englewood Cliffs: Prentice-Hall.

Moe, Terry M. 1984. The new economics of organization. American Journal of Political Science 28: 739-777.

Mudge, Stephanie Lee. 2006. What is neo-liberalism? Socio-Economic Revue 6: 703-731.

Müller-Böling, Detlef. 2000. Die entfesselte Hochschule. Gütersloh: Bertelsmann Stiftung.

Münch, Richard. 2011. Akademischer Kapitalismus. Zur politischen Ökonomie der Hochschulreform. Berlin: Suhrkamp.

Neumann, Ruth, Sharon Parry, und Tony Becher. 2002. Teaching and learning in their disciplinary contexts: A conceptual analysis. Studies in Higher Education 27 (4): 405417.

Nickel, Sigrun. 2007. Partizipatives Management von Universitäten. Zielvereinbarungen Leitungsstrukturen - staatliche Steuerung. München: Hampp.

Nicolae, Stefan, Martin Endreß, Oliver Berli, und Daniel Bischur, Hrsg. 2019. (Be)Werten. Beiträge zur sozialen Konstruktion von Wertigkeit. Wiesbaden: Springer VS.

Niedersächsisches Ministerium für Wissenschaft und Kultur. o. J. Modellbeschreibungen der Leistungsbezogenen Mittelzuweisung der Hochschulen in staatlicher Verantwortung (gültig ab 2016). https://www.mwk.niedersachsen.de/startseite/hochschulen/hochschulpolitik/hochschulentwicklungsvertrag_und_zielvereinbarungen/ hochschulentwicklungsvertrag-und-zielvereinbarungen-als-elemente-der-hochschulsteuerung-in-niedersachsen-131463.html.

Noordegraaf, Mirko. 2007. From „pure“ to „hybrid“ professionalism: Present-day professionalism in ambiguous public domains. Administration and Society 39: 761-785.

Noordegraaf, Mirko. 2015. New Governance and Professionalism. In Restructuring Welfare Governance. Marketization, Managerialism and Welfare State Professionalism, Hrsg. Tanja Klenk und Emmanuele Pavolini, 121-144. Cheltenham: Edward Elgar.

OECD. 1995. Governance in transition: Public management reforms in OECD countries. Paris: OECD. 
Oevermann, Ulrich. 1981. Fallrekonstruktionen und Strukturgeneralisierung als Beitrag der objektiven Hermeneutik zur soziologisch-strukturtheoretischen Analyse. Manuskript. https://d-nb.info/974365483/34.

Oevermann, Ulrich. 2000. Die Methode der Fallkonstruktion in der Grundlagenforschung sowie der klinischen und pädagogischen Praxis. In Die Fallrekonstruktion. Sinnverstehen in der sozialwissenschaftlichen Forschung, Hrsg. Klaus Kraimer, 58-156. Frankfurt a. M.: Suhrkamp.

Osterloh, Margit. 2010. Governance by numbers. Does it really work in research? Analyse und Kritik 32 (2): 267-283.

Osterloh, Margit, und Bruno S. Frey. 2015. Ranking games. Evaluation Review 39 (1): $102-129$.

Peter, Lothar. 2010. Der Homo academicus. In Diven, Hacker, Spekulanten. Sozialfiguren der Gegenwart, Hrsg. Stephan Moebius und Markus Schroer, 206-218. Berlin: Suhrkamp.

Petersen, Thomas. 2020. Die Forschung ist frei, aber ... Eine Umfrage des Instituts für Demoskopie Allensbach zur Freiheit an den Universitäten. Forschung Und Lehre 3: 194-197.

Pollitt, Christopher, and Geerd Bouckaert. 2000. Public management reform: A comparative analysis. Oxford: Oxford University Press.

Power, Michael. 1997. Audit society - Rituals of verification. Oxford: Oxford University Press.

Przyborski, Aglaja, und Monika Wohlrab-Sahr. 2014. Qualitative Sozialforschung. Ein Arbeitsbuch, 4., erw. Aufl. München: Oldenbourg.

Ptak, Ralf. 2007. Grundlagen des Neoliberalismus. In Kritik des Neoliberalismus, Hrsg. Christoph Butterwegge, Bettina Lösch, und Ralf Ptak, 13-86. Wiesbaden: VS.

Riegraf, Birgit. 2018. Zwischen Exzellenz und Prekarität. Über den Wettbewerb und die bedingte Öffnung der Universitäten für Wissenschaftlerinnen. In Prekäre Gleichstellung. Geschlechtergerechtigkeit, soziale Ungleichheiten und unsichere Arbeitsverhältnisse in der Wissenschaft, Hrsg. Mike Laufenberg, Petra Erlemann, Maria Norkus, und Grit Petschick, 241-256. Wiesbaden: VS.

Ringer, Fritz K. 1987. Die Gelehrten. Der Niedergang der deutschen Mandarine 18901933. München: DTV.

Röbken, Heinke, and Marcel Schütz. 2013. Hochschulräte. Eine empirische Bestandsaufnahme ihrer Zusammensetzung. Die Hochschule 22 (2): 96-107.

Rogge, Jan-Christoph. 2017. Wissenschaft zwischen Lebensform und Karrierejob. Dissertation, Technische Universität Berlin.

Sauder, Michael, und Wendy Nelson Espeland. 2009. The discipline of rankings: Tight coupling and organizational change. American Sociological Review 74 (1): 63-82.

Schade, Angelika. 2004. Shift of paradigm in quality assurance in Germany: More autonomy but multiple quality assessment? In Accreditation and evaluation in the European higher education area, Hrsg. Stefanie Schwarz und Don F. Westerheijden, 175-196. Dordrecht: Kluwer.

Schimank, Uwe. 1981. Identitätsbehauptung in Arbeitsorganisationen. Individualität in der Formalstruktur. Frankfurt a. M.: Campus. 
Schimank, Uwe. 2000. Handeln und Strukturen. Einführung in die akteurtheoretische Soziologie. München: Juventa.

Schimank, Uwe. 2009. Governance-Reformen nationaler Hochschulsysteme - Deutschland in internationaler Perspektive. In Neue Steuerung von Hochschulen - Eine Zwischenbilanz, Hrsg. Jörg. Bogumil und Rolf G. Heinze, 123-137. Berlin: Sigma.

Schimank, Uwe. 2010. Reputation statt Wahrheit: Verdrängt der Nebencode den Code? Soziale Systeme 16: 233-242.

Schimank, Uwe. 2012a. Krise - Umbau - Umbaukrise? Zur Lage der deutschen Universitäten. In Die Rolle der Universität in Wirtschaft und Gesellschaft, Hrsg. Klaus Dicke, Uwe Cantner, und Matthias Ruffert, 41-54. Jena: IKS Garamond, Edition Paideia.

Schimank, Uwe. 2012b. Wissenschaft als gesellschaftliches Teilsystem. In Handbuch Wissenschaftssoziologie, Hrsg. Sabine Maasen, Mario Kaiser, Martin Reinhart, und Barbara Sutter, 113-123. Wiesbaden: Springer VS.

Schimank, Uwe. 2014. Identitätsbedrohungen und Identitätsbehauptung: Professoren in reformbewegten Universitäten. In Formalität und Informalität in Organisationen, Hrsg. Victoria von Groddeck und Sylvia M. Wilz, 277-296. Wiesbaden: VS.

Schimank, Uwe. 2015. ,New public management" as de-professionalization - Conceptual reflections with some applications to school teachers. In Restructuring Welfare Governance - Marketization, Managerialism and Welfare State Professionalism, Hrsg. Tanja Klenk und Emmanuele Pavolini, 183-199. Cheltenham: Edward Elgar.

Schimank, Uwe, and Stefan Lange. 2009. Germany: A latecomer to new public management. In University governance - Western European comparative perspectives, ed. Catherine Paradeise, Emanuela Reale, Ivar Bleiklie, and Ewan Ferlie, 51-75. Dordrecht: Springer.

Schomburg, Harald, Choni Flöther, und Vera Wolf. 2012. Wandel von Lehre und Studium an deutschen Hochschulen - Erfahrungen und Sichtweisen der Lehrenden. Projektbericht. Kassel: Internationales Zentrum für Hochschulforschung (INCHER-Kassel), Universität Kassel.

Scott, W. Richard. 1966. Konflikte zwischen Spezialisten und bürokratischen Organisationen. In Bürokratische Organisation, Hrsg. Renate Mayntz, 201-216. Köln: Kiepenheuer \& Witsch.

Serrano-Velarde, Kathia. 2008. Evaluation, Akkreditierung und Politik. Zur Organisation von Qualitätssicherung im Zuge des Bolognaprozesses. Wiesbaden: VS.

Serrano-Velarde, Kathia. 2009. Der Bolognaprozess und die europäische Wissensgesellschaft. SozW Soziale Welt 60 (4): 339-352.

Shin, Jung Cheol, Akira Arimoto, William K. Cummings, und Ulrich Teichler. 2014. Teaching and research in contemporary higher education. Systems, activities, and rewards. Dordrecht: Springer.

Shore, Chris. 2008. Audit culture and illiberal governance: Universities and the politics of accountability. Anthropological Theory 8: 278-298.

Simon, Dieter. 1991. Die Universität ist verrottet. DER SPIEGEL 50: 52-53.

Snow, Charles Percy. 1959. The two cultures and the scientific revolution. London: Cambridge University Press. 
Statistisches Bundesamt. 2017. Fachserie 11 Reihe 4.4, 2016, Bildung und Kultur - Personal an Hochschulen. https://www.statistischebibliothek.de/mir/servlets/ MCRFileNodeServlet/DEHeft_derivate_00033169/2110440167004.pdf.

Strauss, Anselm. 1959. Spiegel und Masken. Die Suche nach Identität. Frankfurt a. M. [1974]: Suhrkamp.

Taylor, Frederick W. 1913. Die Grundsätze wissenschaftlicher Betriebsführung. Weinheim [1977]: Beltz.

Teelken, Christine. 2012. Compliance or pragmatism: How do academics deal with managerialism in higher education? A comparative study in three countries. Studies in Higher Education 37: 271-290.

Teichler, Ulrich. 2014. Teaching and research in Germany: The notions of university professors. In Teaching and research in contemporary higher education. Systems, activities, and rewards, Hrsg. Jung Cheol Shin, Akira Arimoto, William K. Cummings, und Ulrich Teichler, 61-87. Dordrecht: Springer.

Thomas, Robyn, und Annette Davies. 2005. Theorizing the micro-politics of resistance: New public management and managerial identities in the UK public services. Organization Studies 26: 683-706.

Tremp, Peter, Hrsg. 2010. „Ausgezeichnete Lehre!“ Lehrpreise an Universitäten. Erörterungen - Konzepte - Vergabepraxis. Münster: Waxmann.

Voswinkel, Stephan. 2001. Anerkennung und Reputation. Die Dramaturgie industrieller Beziehungen. Mit einer Fallstudie zum „Bündnis für Arbeit“. Konstanz: UVK.

Voswinkel, Stephan. 2011. Zum konzeptionellen Verhältnis von „Anerkennung“ und „Interesse“. Arbeits- und Industriesoziologische Studien 4 (2): 45-58.

Voswinkel, Stephan, und Gabriele Wagner. 2012. Die Person als Leistungskraft: Anerkennungspolitiken in Organisationen. Leviathan 40 (4): 591-608.

Wetzel, Dietmar J. 2013. Soziologie des Wettbewerbs. Eine kultur- und wirtschaftssoziologische Analyse der Marktgesellschaft. Wiesbaden: Springer VS.

Whitley, Richard, und Jochen Gläser, Hrsg. 2007. The changing governance of the sciences: The advent of research evaluation systems. Dordrecht: Springer.

Wilkesmann, Uwe. 2013. Effects of transactional and transformational governance on academic teaching: Empirical evidence from two types of higher education institutions. Tertiary Education and Management 19 (4): 281-300.

Wilkesmann, Uwe, und Christian Schmid. 2012. The impacts of new governance on teaching at German universities. Findings from a national survey. Higher Education 63: 33-52.

Wilkesmann, Uwe, und Christian Schmid. 2014. Intrinsic and internalized modes of teaching motivation. Evidence-based HRM 2 (1): 6-27.

Willke, Gerhard. 2003. Neoliberalismus. Frankfurt a. M.: Campus.

Wissenschaftsrat. 2018. Hochschulbildung im Anschluss an den Hochschulpakt 2020. Köln: Wissenschaftsrat.

Witte, Johanna. 2006. Change of degrees and degrees of change. Comparing adaptations of European higher education systems in the context of the Bologna process. Enschede: University of Twente, CHEPS.

Wollin-Giering, Susanne, and Jochen Gläser. 2016. Entwerfen lernen. Die Integration von Lehre, Forschung und Berufspraxis in entwerfenden Disziplinen. Technische Universität Berlin: Ms. 
Ybema, Sierk, Robyn Thomas, und Cynthia Hardy. 2016. Organizational change and resistance: An identity perspective. In The SAGE handbook of resistance, Hrsg. David Courpasson und Steven Vallas, 386-404. Los Angeles: SAGE.

Ylijoki, Oili-Helena. 2003. Entangled in academic capitalism? A case study on changing ideals and practices of university research. Higher Education 45: 307-335.

Ylijoki, Oili-Helena. 2014. University under structural reform: A micro-level perspective. Minerva 52: 55-75.

Zechlin, Lothar. 2017. Wissenschaftsfreiheit und Organisation - Die „Hochschullehrermehrheit" im Grundrechtsverständnis der autonomen Universität. Ordnung der Wissenschaft 3: 161-174.

Ziman, John. 2000. Real science. What it is, and what it means. Cambridge: Cambridge University Press.

Zimmermann, Karin, Sigrid Metz-Göckel, und Marion Kamphans. 2008. Hochschul- und Geschlechterforschung im Diskurs. In Perspektiven der Hochschulforschung, Hrsg. Karin Zimmermann, Marion Kamphans, und Sigrid Metz-Göckel, 11-33. Wiesbaden: VS.

Open Access Dieses Kapitel wird unter der Creative Commons Namensnennung 4.0 International Lizenz (http://creativecommons.org/licenses/by/4.0/deed.de) veröffentlicht, welche die Nutzung, Vervielfältigung, Bearbeitung, Verbreitung und Wiedergabe in jeglichem Medium und Format erlaubt, sofern Sie den/die ursprünglichen Autor(en) und die Quelle ordnungsgemäß nennen, einen Link zur Creative Commons Lizenz beifügen und angeben, ob Änderungen vorgenommen wurden.

Die in diesem Kapitel enthaltenen Bilder und sonstiges Drittmaterial unterliegen ebenfalls der genannten Creative Commons Lizenz, sofern sich aus der Abbildungslegende nichts anderes ergibt. Sofern das betreffende Material nicht unter der genannten Creative Commons Lizenz steht und die betreffende Handlung nicht nach gesetzlichen Vorschriften erlaubt ist, ist für die oben aufgeführten Weiterverwendungen des Materials die Einwilligung des jeweiligen Rechteinhabers einzuholen.

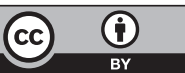

